\title{
Observation-based source terms in the third-generation wave model WAVEWATCH
}

\author{
Stefan Zieger ${ }^{a, *}$, Alexander V. Babanin ${ }^{\mathrm{a}}$, W. Erick Rogers ${ }^{\mathrm{b}}$, Ian R. Young ${ }^{\mathrm{c}}$ \\ ${ }^{a}$ COEST, Swinburne University of Technology, Melbourne, Australia \\ ${ }^{b}$ Naval Research Laboratory, Stennis Space Center, U.S.A. \\ ${ }^{c}$ Australian National University, Canberra, Australia
}

\begin{abstract}
Measurements collected during the AUSWEX field campaign, at Lake George (Australia), resulted in new insights into the processes of wind wave interaction and whitecapping dissipation, and consequently new parametrizations of the input and dissipation source terms. The new nonlinear wind input term developed accounts for dependence of the growth on wave steepness, airflow separation, and for negative growth rate under adverse winds. The new dissipation terms feature the inherent breaking term, a cumulative dissipation term and a term due to production of turbulence by waves, which is particularly relevant for decaying seas and for swell. The latter is consistent with the observed decay rate of ocean swell. This paper describes these source terms implemented in WAVEWATCH III $®$ and evaluates the performance against existing source terms in academic duration-limited tests, against buoy measurements for windsea-dominated conditions, under conditions of extreme wind forcing (Hurricane Katrina), and against altimeter data in
\end{abstract}

${ }^{*}$ Corresponding author. Now at Bureau of Meteorology, GPO Box 1289, Melbourne, VIC, 3001, Australia. Tel: +61 396694813 Fax: +61 396694699

Email address: szieger@bom.gov.au (Stefan Zieger)

Preprint submitted to Ocean Modelling

July 17, 2015

(C) 2015. This manuscript version is made available under the Elsevier user license http://www.elsevier.com/open-access/userlicense/1.0/ 
global hindcasts. Results show agreement by means of growth curves as well as integral and spectral parameters in the simulations and hindcast.

Keywords: wave modelling, wind input, negative input, whitecapping dissipation, swell dissipation

\section{Introduction}

Numerical simulation of the evolution of the wind-wave energy density spectrum is routinely conducted in wave forecasting and hindcasting. Windwave evolution in third-generation models is described by the wave action balance equation (1) which considers all energy fluxes and source terms, represented by physical processes that contribute to wind-wave growth. The wave action balance equation can be written as (Gelci et al., 1957; Tolman, 1990; Komen et al., 1994):

$$
\frac{\partial}{\partial t} N+\nabla \cdot \dot{\mathbf{x}} N+\frac{\partial}{\partial k} \dot{k} N+\frac{\partial}{\partial \theta} \dot{\theta} N=\frac{S_{t o t}}{\sigma}
$$

The first term of the left hand side of (1) represents the rate of net change

10 of wave action $N=F(k, \theta, t, \mathbf{x}) / \sigma$, that is a function of the variance density spectrum $F(k, \theta, t, \mathbf{x})$ and intrinsic (radian) frequency of wave components $\sigma=2 \pi f$. The variance density spectrum is usually referred to as the energy in the wave modeling community. The wave spectrum $F$ is five-dimensional, that is a function of wavenumber $k$, direction $\theta$, time $t$ and space $\mathbf{x}$. Wave action $N$ is conserved in the propagation term in cases where currents are present (e.g. Whitham, 1965) which is generally not the case when using spectral wave energy $F$ in the balance equation (Longuet-Higgins and Stewart, 1961, 1962). The second term in equation (1) represents the advection 
of wave action $\dot{\mathbf{x}}=d \mathbf{x} / d t=\mathbf{c}_{\mathbf{g}}+\mathbf{U}$ at group velocity $\mathbf{c}_{\mathbf{g}}$ relative to the mean current $\mathbf{U}$, where $\nabla$ is the differential operation in two-dimensional space. Terms three and four describe the rate of change in spectral space in which $\dot{k}=d k / d t=c_{k}$ denotes the propagation speed in wavenumber space and $\dot{\theta}=d \theta / d t=c_{\theta}$ is the propagation speed in direction. The total source term $S_{\text {tot }}$ on the right-hand side of the action balance equation (1) is based on all considerable physical processes, all of which are described by spectral functions. WAVEWATCH contains parameterizations for a number of different processes which can be individually activated (Tolman et al., 2014):

$$
S_{t o t}=S_{i n}+S_{d s}+S_{n l}+S_{b o t}+S_{d b}+S_{t r}+S_{s c}+S_{i c e}+S_{r e f}
$$

for example, wind input $S_{i n}$, wave dissipation $S_{d s}$, nonlinear wave-wave interaction $S_{n l}$, wave-bottom interactions $S_{b o t}$, depth-induced breaking $S_{d b}$, triad wave-wave interactions $S_{t r}$, bottom scattering $S_{s c}$, wave-attenuation due to ice $S_{i c e}$ and reflection of waves due to shore lines and icebergs $S_{r e f}$.

For deep water it is generally accepted that the total source terms (2) is based on three main physical processes: atmospheric input $S_{i n}$, wave dissipation $S_{d s}$, nonlinear interactions wave-wave interaction $S_{n l}$ (e.g. Komen et al., 1994; Young, 1999; Tolman et al., 2014). Babanin and Van der Westhuysen (2008), Ardhuin et al. (2010), and Babanin (2011) pointed out that these individual terms have to be further subdivided. For example, $S_{d s}$ is a sum of inherent and cumulative wave-breaking dissipation. In reality, further mechanisms have to be considered, such as dissipation due to interaction with turbulence in the air, with the adverse wind etc., and provision should 
be made to let individual dissipation mechanisms cease as appropriate while other dissipation sinks continue. This is a different concept to the original bulk parametrizations for deep water (e.g. Komen et al., 1994). Similar logic also applies to the other source terms. In the presence of currents and in water of finite depth additional processes become significant in (2). For example, wave-bottom interactions and depth-induced breaking have to be considered in the total source term (Tolman et al., 2014). This paper focusses on wind input $S_{i n}$ and wave dissipation $S_{d s}$ due to whitecapping and due to wave-turbulence production. The source term is labeled BYDRZ after major contributers to this project and is available in WAVEWATCH 4.18 (with extension in version 5.08). The implementation was part of the U.S. National Oceanographic Partnership Program (NOPP) wave model improvement project (Tolman et al., 2011, 2013).

Here, the focus is on input and dissipation parameterizations obtained from field experiments, carried out during the Australian Shallow Water Experiment (AUSWEX) at Lake George, New South Wales, Australia. The boundary layer study of this experiment produced a wind input term as described in Donelan et al. (2005) and was later parameterised by Donelan et al. (2006) and Babanin et al. (2007a) as spectral functions to be used in wave models. For wave breaking and dissipation, Lake George also revealed a number of new features which were later parameterized as spectral functions to be used in spectral models (Babanin et al., 2001, 2007b; Babanin and Young, 2005; Young and Babanin, 2006).

65

Besides WAVEWATCH, the new input and whitecapping source terms have been implemented and calibrated for two wave models: (i) the one- 
dimensional research model WAVETIME (van Vledder, 2002) with (ii) the new physics in WAVETIME (Tsagareli, 2009; Tsagareli et al., 2010), (iii) SWAN ("Simulating WAves Nearshore") (Booij et al., 1999) with (iv) the new physics in SWAN (Rogers et al., 2012). It should be stressed here, that the SWAN model is designed for near-shore applications and until now the skill of the source terms in more realistic open ocean conditions was undetermined. The parameterizations described here diverge from the ones in Rogers et al. (2012). Modifications include the vector form of the wave supported stress and the production of turbulence by waves (Babanin, 2011). For the negative input, the omni-directional term with constant coefficient $f_{e}$ after Ardhuin et al. (2009) was replaced by the directional term of Donelan (1999).

The objective of this study is to demonstrate the performance of the observation-based source terms for wind-dominated conditions in durationlimited simulations, global hindcasts and other specific conditions (see later $\S 3)$. In the academic test, when applicable, the model skill is evaluated for two formulations of nonlinear interactions: the discrete interactive approximation parameterization (DIA hereafter, Hasselmann et al., 1985) and exact computations (XNL for exact nonlinear hereafter) using the WebbResio-Tracy method (WRT, Tracy and Resio, 1982). The latter provides accurate estimates of energy fluxes within the wave system, in addition to those due to wind and breaking, but is computational expensive. The former is a fast approximation and thus routinely employed in operational forecasting. WAVEWATCH includes various source term packages (or physics): TC96 (Tolman and Chalikov, 1996), WAM3 (Snyder et al., 1981; Komen 
et al., 1984), WAM4+ (or ECWAM) (Janssen, 1991; Bidlot et al., 2007), and TEST451 (Ardhuin et al., 2009, 2010; Rascle and Ardhuin, 2013). Note that, WAM4+ refers to the input and dissipation terms of the full ECWAM physics package described in Bidlot (2012a). Here, model skill is evaluated against existing packages TC96 and TEST451 in detail since both cover physical aspects similar to the BYDRZ source terms, such as a swell dissipation and a whitecapping dissipation that consists of multiple terms. Although tuned for ocean-scale applications, the TC96 input features a negative term for waves travelling at large angles in the form of swell. In addition, the TC96 dissipation consists of a conventional low frequency dissipation term and a high frequency dissipation (Tolman and Chalikov, 1996; Tolman, 2002). The validation report Tolman (2002) showed positive biases in the tropics suggesting insufficient swell attenuation and the need for "negative input" as proxy for swell attenuation. The shortcoming of this low frequency dissipation ("negative input") is that it is calculated from friction velocity and thus wind speed and does not dissipate swells in absence of wind (Tolman and Chalikov, 1996; Tolman, 2002). The input in TEST451 accounts for swell dissipation due to interaction with the air and thus can become negative (Ardhuin et al., 2010, 2011a). The dissipation includes a threshold and cumulative term.

The outline of the paper is as follows. Section 2 provides detailed description of the wind input term and the dissipation source terms implemented in WAVEWATCH. Section 3 contains description of the setup and results for the idealised academic tests and simulations selected to test the performance 115 of the observation-based source terms. In Section 4 the results are discussed and the conclusions are formulated in Section 5 . 


\section{Source terms}

\subsection{Wind input}

The wind input function represents the energy flux transferred from wind to waves. This term is due to form drag, i.e. pressure acting on the surface slope of the waves (e.g. Donelan et al., 2006). AUSWEX data analysis and the wind input parameterization reported by Donelan et al. (2005, 2006) and Babanin et al. (2007a) shows dependencies that have not been reported in previous experiments. Measurements of wave growth during AUSWEX were available for a range of wind-forcing conditions including very young waves $U_{10} / c_{p}=5.1-7.6\left(c_{p}\right.$ is the phase speed at the spectral peak $)$ of varying steepness. This unique dataset revealed a number of new features: (i) full airflow separation with a relative reduction of wind input for conditions of strong winds/steep waves, if compared with its extrapolation from the moderate conditions (Donelan et al., 2006); (ii) dependence of the wave growth rate on wave steepness which make the input term a nonlinear function of the wave spectrum (Donelan et al., 2006); and (iii) enhancement of $S_{i n}$ in the presence of wave breaking (Babanin et al., 2007a).

Donelan et al. (2006) described the effect of full air-flow separation in which the wind detaches from the flow, skipping the wave troughs before it re-attaches on the windward side of the wave crest. Reul et al. (1999) investigated full air-flow separation in laboratory experiments. Compared to the non-separated flow, the imposed wind input pressure is relatively weaker under such conditions. Based on the observations, the effect was parameterised by Donelan et al. (2006) and included in the new wind input term. 
The wind input $S_{i n}=\gamma \sigma N$ is defined as a function of the wave action spectrum $N$ and the growth rate of the wind-waves $\gamma$. AUSWEX field data, however, revealed that the wind-wave growth rate $\gamma$ depends on wave steepness $a k$ ( $a$ being the wave amplitude). Donelan et al. (2006) showed that wave steepness is connected to the phase shift as well as the normalised induced pressure amplitude, and that potential flow is only valid as $a k \rightarrow 0$. In the final parameterization in the air the wave steepness $a k$ is replaced by the spectral saturation $\sqrt{B_{n}}$ (6) following Phillips (1984). Thus, the growth rate $\gamma$ obtained from the Lake George data is also a function of the wave spectrum, which in turn makes the wind input non-linearly dependent on the spectrum.

Furthermore, laboratory experiments conducted by Donelan (1999) showed that under adverse winds, waves are strongly attenuated and the magnitude of the negative growth rate is 2.5 times smaller than for positive growth for similar winds. Here, this parameterization has been included in the wind input term as a proxy of directional swell attenuation due to turbulent interaction with the atmosphere in the presence of wind.

\subsubsection{Implementation}

The parameterization of the wind input $S_{i n}$, as proposed by Donelan et al. (2006), is designed for young wind-waves to mature seas, i.e. for conditions encompassing light, moderate, and strong wind forcing. The proposed wind input is given in (3)-(7) (Donelan et al., 2006; Tsagareli et al., 2010; Rogers et al., 2012). 


$$
\begin{aligned}
S_{i n}(k, \theta) & =\frac{\rho_{a}}{\rho_{w}} \sigma \gamma(k, \theta) N(k, \theta) \\
\gamma(k, \theta) & =G \sqrt{B_{n}(k)} W(k, \theta) \\
G & =2.8-\left[1+\tanh \left(10 \sqrt{B_{n}(k)} W(k, \theta)-11\right)\right] \\
B_{n}(k) & =A(k) N(k) \sigma k^{3} \\
W(k, \theta) & =\left[\frac{U}{c} \cos \left(\theta-\theta_{w}\right)-1\right]^{2}
\end{aligned}
$$

165

In $(3)-(7) \rho_{a}, \rho_{w}$ are the densities of air and water, respectively, $U$ is the wind speed relative to the direction of the waves $\left(\theta-\theta_{w}\right), c$ refers to the phase speed, $k$ is the wavenumber, and $B_{n}(k)$ is the spectral saturation which is local in wavenumber space. Spectral saturation (6), introduced by Phillips (1984), as a convenient measure of steepness $a k$, was implemented as a function of the omni-directional wave energy density (Banner et al., 2002) and narrowness $A(k)$ of the directional distribution at a frequency (Babanin and Soloviev, 1987, 1998b). The omni-directional action density is obtained by integration over all directions: $N(k)=\int N(k, \theta) d \theta$. The inverse of the directional spectral narrowness $A(k)$ is defined as

$$
A^{-1}(k)=\int_{0}^{2 \pi}\left[N(k, \theta) / N_{\max }(k)\right] d \theta
$$

and is given by integrating the normalised energy density spectrum over all directions, where the normalization is based on the maximum value in the dominant wave direction $N_{\max }(k)=\max \{N(k, \theta)\}$, for all directions $\theta \in[0,2 \pi]$ (Babanin and Soloviev, 1987).

The directional narrowness parameter (8) uses the maximum value for normalization. In the presence of side lobes, the value of $A$ decreases because 
side lobes increase the total area of the directional distribution at that frequency and integration is performed across a broader range of directions.

Donelan et al. (2006) measured the growth rate (4) based on winds $10 \mathrm{~m}$ above the mean surface. Wave models typically employ friction velocity $u_{\star}^{2}=\tau / \rho_{a}$. From Snyder et al. (1981) and Komen et al. (1984) wind speed scaling $U=28 u_{\star}$ is adopted.

$$
\begin{aligned}
& W_{1}(k, \theta)=\max ^{2}\left\{0,28 \frac{u_{\star}}{c} \cos \left(\theta-\theta_{w}\right)-1\right\} \\
& W_{2}(k, \theta)=\min ^{2}\left\{0,28 \frac{u_{\star}}{c} \cos \left(\theta-\theta_{w}\right)-1\right\}
\end{aligned}
$$

The directional distribution of $W$ is implemented as the sum of favourable winds (9) and adverse winds (10) in which the latter can be interpreted as a proxy for the swell momentum feedback mechanism:

$$
W(k, \theta)=W_{1}(k, \theta)-a_{0} W_{2}(k, \theta),
$$

so that spectral partitions $W_{1}$ and $W_{2}$ complement one another (i.e. $W=$ $\left.\left\{W_{1} \cup W_{2}\right\}\right)$. For adverse winds the reported growth rate is negative and $40 \%$ (i.e. $=2.5^{-1}$ ) of the growth rate of following winds (Donelan et al., 2006). The negative input is applied after the constraint to match the wave supported stress is met (see $\S 2.1 .2$ ). In this case the negative growth rate is approximately an order of magnitude less than the value reported, however, the value of $a_{0}$ is a tuning parameter in the parameterization of the input.

\subsubsection{Wind stress}

The momentum flux between the atmosphere and the ocean is determined by the wind stress. Several authors (e.g. Janssen, 1989, 1991; Chalikov 
and Makin, 1991) showed that the momentum flux $\vec{\tau}$ (total stress) is the contribution of wave fluctuations $\vec{\tau}_{w}$ and turbulent fluctuations $\vec{\tau}_{t}$. Close to the surface, the contribution to the total stress is due to wave-induced stress $\vec{\tau}_{w}$, turbulent stress, and viscous stress $\vec{\tau}_{v}$. At the surface, the turbulent momentum flux in the boundary layer approaches zero and therefore turbulence vanishes (e.g. Tsagareli et al., 2010). As a result, the total stress at the surface can be written as:

$$
\vec{\tau}=\vec{\tau}_{v}+\vec{\tau}_{w}
$$

Janssen (1991, and variants) calculate the wave-induced stress directly by integrating the momentum-flux and accounts for the modification of the boundary layer based on the roughness length of the sea surface. In the approach presented here, the calculation of wave-induced stress is based on empirical relations which requires knowledge of the drag coefficient $C_{d}$ and the viscous drag coefficient $C_{v}$. The drag coefficient is used to translate winds in the boundary layer to the wind stress at the surface. The total stress can then be computed with $\vec{\tau}=\rho_{a} C_{d} U_{10}^{2}=\rho_{a} u_{\star}^{2}$ and the viscous stress with ${ }_{215} \tau_{v}=\rho_{a} C_{v} U_{10}^{2}$, where $u_{\star}$ is the friction velocity. A comparison of stresses calculated with different models is presented later in the discussion $\S 4$ and Figure 18.

For the drag coefficient, parameterization (13) was selected as proposed by Hwang (2011) which accounts for saturation, and even decrease in magnitude for extreme winds, of the sea drag at wind speeds in excess of $30 \mathrm{~m} \mathrm{~s}^{-1}$. To prevent $u_{\star}$ from asymptoting to zero at very strong winds $U_{10} \geq 50.33 \mathrm{~m} \mathrm{~s}^{-1}$, expression (13) was modified (i.e. capped) to yield $u_{\star}=2.026 \mathrm{~m} \mathrm{~s}^{-1}$ (Rogers 
et al., 2012).

$$
C_{d} \times 10^{4}=8.058+0.967 U_{10}-0.016 U_{10}^{2}
$$

Tsagareli et al. (2010) parameterised the viscous drag coefficient as a function of wind speed applying data from Banner and Peirson (1998):

$$
C_{v} \times 10^{3}=1.1-0.05 U_{10} .
$$

The wave-supported stress $\vec{\tau}_{w}$ in equation (12) is used as the principal constraint for the wind input and cannot exceed the total stress $\vec{\tau} \leq \vec{\tau}_{t o t}$. The wave-supported stress $\vec{\tau}_{w_{\mathrm{HF}}}$ can be calculated by integration over the wind-momentum-input function:

$$
\vec{\tau}_{w_{\mathrm{HF}}}=\rho_{w} g \int_{0}^{2 \pi} \int_{0}^{k_{\max }} \frac{S_{i n}\left(k^{\prime}, \theta\right)}{c}(\cos \theta, \sin \theta) d k^{\prime} d \theta .
$$

Using stress components in the normal stress computation in equation (15) yields overall lower values for $\tau_{w_{\mathrm{HF}}}$ compared to integration over the nondirectional wind-momentum-input $\tau_{w_{\mathrm{HF}}}=\int S_{i n}\left(k^{\prime}\right) c^{-1} d k^{\prime}$. This difference can be attributed to stresses away from the main stress direction, and as a result the magnitude of the stress is reduced. Computation of the wavesupported stress $\vec{\tau}_{w_{\mathrm{HF}}}$ (15) includes the resolved part of the spectrum up to the highest discrete wavenumber $k_{\max }$, as well as the stress supported by short waves (subscript HF). To account for the latter, an $f^{-5}$ diagnostic tail up to $10 \mathrm{~Hz}$ is assumed beyond the highest frequency in the energy density spectrum. Specifically, this makes the diagnostic tail at the high frequency limit of the input term $S_{\text {in }}$ proportional to spectral slope $f^{-2}$ (the input term has exactly this shape for a $f^{-5}$ tail in $F(f)$; Rogers et al., 2012). In order 
to satisfy the constraint and in the case of $\vec{\tau}>\vec{\tau}_{\text {tot }}$, a wavenumber dependent factor $L$ is applied to reduce energy from the high frequency part of the spectrum: $S_{\text {in }}\left(k^{\prime}\right)=L\left(k^{\prime}\right) S_{\text {in }}\left(k^{\prime}\right)$ with

$$
L\left(k^{\prime}\right)=\min \left\{1, \exp \left(\delta\left[1-28 u_{\star} / c\right]\right)\right\} .
$$

The reduction (16) is a function of wind speed and phase speed and follows an exponential form designed to reduce energy from the discrete part of the spectrum. The strength of reduction is controlled by the parameter $\delta$, which has a greater impact at high frequencies and only little impact on the energy-dominant part of the spectrum. The value of $\delta$ is dynamically calculated by iteration at each integration time step (Tsagareli et al., 2010). The deviation from the original input term formulated by Donelan et al. (2006) is depicted later in $§ 3.2$, Figure 4 . It is fair to say, that the reduction of the input term $S_{\text {in }}$ is a form of implicit dissipation of shorter waves.

\subsection{Wave energy dissipation}

Wave energy dissipation is attributed to wave-breaking and swell attenuation and is implemented as a negative contribution in the total source term equation (2). Dissipation of wave energy implemented in TC96, TEST451, and BYDRZ, are on physical grounds and much more advanced than that of WAM3 and WAM4+ (ECWAM). Until recently, wave dissipation has been used as a tuning parameter to balance residual energy of the input term in operational wave models (Tolman and Chalikov, 1996). Observations and numerical modelling provided explicit parameterizations of wave dissipation which included a cumulative term, separate versions of which were introduced 
by Donelan (2001) and Babanin and Young (2005) and Young and Babanin 265 (2006), and a threshold term. Analysis of field data yields three physical processes of wave-breaking and spectral dissipation. These are namely: (i) the threshold behaviour of wave breaking initially observed by Banner et al. (2000, 2002), and (ii) the cumulative dissipative effect due to breaking and dissipation of short waves affected by longer waves (Donelan, 2001; Babanin and Young, 2005; Young and Babanin, 2006; Babanin et al., 2010). The threshold behaviour postulates that waves will not break unless they exceed a generic steepness in which case the wave breaking probability depends on the level of exceedance above the threshold. Until the inclusion of TEST451 parameterizations, these features were not accounted for in the dissipation term of spectral wave models. Therefore, the wave whitecapping dissipation term $S_{d s}$ now consists of two distinct terms ("two-phase" behaviour): an inherent breaking component $T_{1}$ and a forced dissipation term $T_{2}$ (Babanin et al., 2010; Rogers et al., 2012). Finally, swell dissipation is based on turbulent kinetic energy dissipation (Babanin, 2011), which is comparable to the swell decay observed over large distances (Ardhuin et al., 2009).

\subsubsection{Wave-breaking and whitecapping dissipation}

The "two-phase" behaviour of the wave breaking and dissipation term is implemented as:

$$
S_{d s}(k, \theta)=\left[T_{1}(k, \theta)+T_{2}(k, \theta)\right] N(k, \theta),
$$

where $T_{1}$ is the inherent breaking term and $T_{2}$ accounts for the cumulative effect of short-wave breaking due to longer waves at each frequency. The inherent breaking term $T_{1}$ is the only breaking-dissipation term if this 
frequency is at or below the spectral peak. Once the peak moves below this particular frequency, $T_{2}$ becomes active and progressively more important as the peak downshifts further.

The threshold action density $N_{\mathrm{T}}$ is calculated as shown in (18), where $k$ is the wavenumber and with $\varepsilon_{\mathrm{T}}=0.035^{2}$ being the empirical constant (Babanin et al., 2007b):

$$
N_{\mathrm{T}}(k)=\frac{\varepsilon_{\mathrm{T}}}{A(k) k^{3}} .
$$

Let the level of exceedance above the critical threshold spectral density (at which stage wave breaking is prominent) be defined as $\Delta(k)=N(k)-N_{\mathrm{T}}(k)$. Furthermore, let $\mathcal{N}(k)$ be a generic action density (see later this section) used for normalization, then the inherent breaking component can be calculated as:

$$
T_{1}(k)=a_{1} A(k) \frac{\sigma}{2 \pi}\left[\frac{\Delta(k)}{\mathcal{N}(k)}\right]^{p_{1}} .
$$

The cumulative dissipation term is not local in frequency space and is based on an integral that grows towards higher frequencies, dominating at smaller scales:

$$
T_{2}(k)=a_{2} \int_{0}^{k} A(k) \frac{\mathbf{c}_{\mathrm{g}}}{2 \pi}\left[\frac{\Delta(k)}{\mathcal{N}(k)}\right]^{p_{2}} d k .
$$

The dissipation terms (19)-(20) depend on five parameters: a generic spectral density $\mathcal{N}(k)$ used for normalization, the group velocity of the waves $\mathbf{c}_{\mathbf{g}}$, and four coefficients $a_{1}, a_{2}, p_{1}$, and $p_{2}$. In previous studies, Babanin et al. (2010) and Tsagareli et al. (2010) selected the spectral density $F=N \sigma$ as 


\subsubsection{Swell dissipation}

Tolman (2002) suggested that additional dissipation is needed in regions dominated by swell. The wave-breaking dissipation expressed in (19)-(20) 


$$
\frac{\partial}{\partial x} a^{2}=-\frac{4}{3} b_{1} k^{2} a^{3},
$$

where $b_{1}$ is a non-dimensional proportionality coefficient, $k$ is wavenum- 
ber, and $a$ is wave amplitude. Noting that the integral of the spectral energy is proportional to $a^{2}$, that $\mathbf{c}_{\mathrm{g}} \partial a^{2} / \partial x=\partial a^{2} / \partial t$, and using the deep water dispersion relation $\mathbf{c}_{\mathbf{g}}=g / 2 \sigma$ and $k=\sigma^{2} / g$, the parameterization for swell (21) can be rewritten as:

$$
\frac{\partial}{\partial t} F=-\frac{2}{3} b_{1} \sigma a k F .
$$

Replacing $a k$ with the non-dimensional measure of spectral steepness (6) and applying (22) to all direction, yields the source term of swell dissipation:

$$
S_{s w l}(k, \theta)=-\frac{2}{3} b_{1} \sigma \sqrt{B_{n}(k)} N(k, \theta) .
$$

Babanin $(2011,2012)$ proposed for the non-dimensional proportionality 360 coefficient a value of $b_{1}=0.004$, which represents an upper bound. When applied to the data from Collard et al. (2009) a lower value of $b_{1}=0.001$ was found (there is a decimal error giving $b_{1}=0.002$ in Babanin, 2011). Young et al. (2013) analysed incoming swell observed by altimeters in the Great Australian Bight and estimated the rate of wave attenuation based on the analytical solution to equation (21). This solution can be expressed in non-dimensional form as:

$$
\frac{H_{0}}{H_{\text {swl }}}=1+\frac{1}{3} b_{1} H_{0} k^{2} x,
$$

where $x$ is the distance away from the origin with initial wave height $H_{0}$ and wavenumber $k$. Young et al. (2013) concluded that the coefficient $b_{1}$ fell between $2 \times 10^{-4}$ and $14 \times 10^{-4}$ where the upper bound $b_{1}=0.0014 \pm 0.0007$ 370 represents the best fit through their altimeter data. 
The analysis undertaken by Young et al. (2013) assumes monochromatic one-dimensional propagation on a flat Earth and it ignores wave field dispersion in both direction and frequency. As such, the result is not a measure of pure swell dissipation and contains attenuation due to dispersion. This was acknowledged by Young et al. (2013) who indicated that the resulting estimate of $b_{1}$ was an upper bound. Utilizing altimeter observations one cannot separate the various active processes. Geographic spreading and wave dispersion dominate wave attenuation over short distances outside the storm area. In the far field swell dissipation will become more important for the decay of swell heights.

To test the effect of wave attenuation due to geographical spreading, wave dispersion and swell dissipation along a great circle, a realistic hindcast was selected. The simulation was initialized with the sea state modelled on 1 June 2013 00:00 UTC but all prescribed fields, that is wind speed and currents, were set to zero. The selected date coincides with a storm event in the South Pacific in which the swell field is allowed to propagate freely over a distance of 9,000 km from New Zealand to Alaska. The setup is inspired by Alves (2006) who developed a technique to study the contribution of ocean swells on the wave climate. Swell height is only considered for the initial swell system depicted in Figure 1 (upper right panel) and integration is limited to the north-north-east sector of the spectrum. Figure 1 depicts maximum swell height as a function of propagation distance together with empirical coefficients with respect to their confidence intervals (shaded areas) estimated from observations of swell decay (Collard et al., 2009) and observations of 395 wave attenuation (Young et al., 2013). To plot the estimated decay from 
previous studies the terminology from Collard et al. (2009, their Eq. (1)) is adopted, where the subscript "0" refers to the point source of the storm on a great circle, $\mathbf{c}_{\mathbf{g}}$ is the group velocity and $\mu\left(\mathrm{m}^{-1}\right)$ is the decay rate. For a constant $\mathbf{c}_{\mathbf{g}}$ and $\mu$, and expressed in integral form with initial wave height $H_{0}$ the decay rate can be written as:

$$
H_{s w l}=H_{0} \exp \left(-\mu \mathbf{c}_{\mathbf{g}} \Delta t\right)
$$

where $\mathbf{c}_{\mathrm{g}} \Delta t$ is the propagation distance along the great circle. Figure 1 shows that in the case of wave propagation only (PR3 UQ) with source terms turned off (solid line with squares) the wave field attenuates due to geographical spreading, dispersion and narrowing of both frequency and direction spectrum (Ardhuin et al., 2009). Attenuation of the swell field in the propagation-only test falls within the confidence intervals of the estimate form altimeter observations (Young et al., 2013) but overestimates in the mean and with distance away from the storm justifying the need for a separate swell dissipation term.

The value for $b_{1}$ estimated from altimeters was performed over distances less than $2500 \mathrm{~km}$ and therefore it can be assumed that geographical spreading and dispersion are the bulk contributors in the estimate. To estimate the approximate contribution of these processes to $b_{1}$, equation (24) was fitted to the propagation-only test which yields a value of $b_{1}=0.0011$ (dashed line in Figure 1). The difference between the estimate from altimeters and the fit to the propagation-only test yield an approximation of $b_{1}$ for swell dissipation: $0.0014-0.0011=0.0003$. In the global hindcast a value of $b_{1}=0.00025$ (dotted line) was found as the best fit, which is slightly below 
the one estimated here. We believe that this difference comes form additional attenuation due to negative wind input. Nonetheless, the attenuation of swell for all cases with source terms depicted in Figure 1 is close to one another. All simulations show that the level of attenuation decreases with distance travelled along the great circle and at a distance of $7,000 \mathrm{~km}$ all parameterizations converge.

Empirical dissipation rates (Collard et al., 2009; Ardhuin et al., 2009) and empirical rates of wave attenuation (Young et al., 2013) were established from conditions where the effect of wind input is negligible, i.e. less than $9 \mathrm{~m} \mathrm{~s}^{-1}$ (Ardhuin et al., 2009) and less than $10 \mathrm{~m} \mathrm{~s}^{-1}$ (Young et al., 2013). In a realistic simulation, the presence of wind would further scale the attenuation rate of swell in the form of negative input and wave breaking dissipation. The latter is not local in frequency space nor direction and if exceeded by the threshold needs to be accounted for. Ardhuin et al. (2010) previously noted that a constant empirical decay coefficient found in Ardhuin et al. (2009) is too strong when deployed in a global hindcast and postulated a scaling with respect to the ratio of surface friction and surface orbital wave velocity by means of magnitude and direction. Going one step further and scaling the swell coefficient $b_{1}$ with steepness (solid line with crosses in Figure 1), see later in equation (28), yields improved results of the model particularly under conditions of opposing swells and swells under large angles. 


\section{Simulations}

\subsection{Parametric spectrum}

To illustrate the characteristics of the dissipation source terms, i.e. wavebreaking/whitecapping dissipation and swell dissipation, a parametric spectrum is applied. Studies of wave frequency spectra suggest that frequency dependence is of the form of $f^{-4}$ closer to the spectral peak while the equilibrium range is closer to $f^{-5}$ (Ewans and Kibblewhite, 1990; Babanin and Soloviev, 1998b; Hwang and Wang, 2001; Long and Resio, 2007; Babanin, 2011; Liu, 2012, amongst others). The original Pierson-Moskowitz (PM) parametric spectrum (Pierson and Moskowitz, 1964) was modified and features a transition from $f^{-4}$ slope to $f^{-5}$ at transition frequency $3 f_{\mathrm{DON}}$, where $f_{\text {DoN }}\left(=0.13 g U_{10}^{-1}\right)$ refers to the peak frequency of the Donelan spectrum for a given wind speed $10 \mathrm{~m}$ above the surface $U_{10}, g$ is the gravitational acceleration, and $\alpha_{\mathrm{DON}}$ is the scale parameter of the Donelan spectrum (Donelan et al., 1985). Here, $\alpha_{\mathrm{DON}}=0.0165 \times \nu_{\mathrm{DON}}{ }^{0.55}$ is a function of non-dimensional peak frequency $\nu_{\mathrm{DON}}=f_{\mathrm{DON}} U_{10} g^{-1}=0.13$. Tsagareli et al. (2010) and Babanin et al. (2010) used a parametric spectrum very similar to the one given in (26).

$$
F(f)= \begin{cases}\alpha_{\mathrm{DON}} \frac{g^{2}}{f^{4} \omega_{\mathrm{DON}}} \exp \left(-f_{\mathrm{DON}} / f^{4}\right) & \text { for } f \leq 3 f_{\mathrm{DON}} \\ F\left(3 f_{\mathrm{DON}}\right) 3 f_{\mathrm{DON}} / f^{5} & \text { for } f>3 f_{\mathrm{DON}}\end{cases}
$$

The directional distribution in the spectrum is calculated following LonguetHiggins (1963): $F(f, \theta)=F(f) \Phi(f, \theta)$, where $\Phi(f, \theta)=\mathcal{A}(s) \cos ^{2 s}(\theta / 2)$. The spreading is controlled by parameter $s$ while $\mathcal{A}(s)$ is a normalization factor so that $\int \Phi(f, \theta) d \theta=1$ and has the form: $2^{2 s-1} \Gamma^{2}(s+1) \pi^{-1} \Gamma^{-1}(2 s+1)$. The 
shape of the omnidirectional parametric spectrum (26) is shown in Figure 2 (top panel) for a wind speed of $8 \mathrm{~m} \mathrm{~s}^{-1}$. The second panel illustrates the shape of the wave dissipation term, including the inherent term $T_{1}$ and cumulative term $T_{2}$. The plot also shows the swell dissipation functions estimated from (23) with $b_{1}=0.00025$ (Babanin, 2011), the parameterization by Ardhuin et al. (2009) with $f_{e}=0.04$, and the negative part of the input by Tolman and Chalikov (1996). Of the three swell dissipation parameterizations, the TC96 swell formulation is an order of magnitude low in comparison. The swell dissipation in TEST451 and BYDRZ is continuous and focussed dominantly on the energy-containing region of the spectrum and in the case of the parametric PM spectrum around the spectral peak. In contrast, the bulk of the wave-breaking and whitecapping dissipation is well above the peak $f_{p}=0.16 \mathrm{~Hz}$ (about three times). In the presence of wind, the integral of the swell dissipation is significantly less than the integral of the wave dissipation and in this example, the ratio of integral dissipation (subscript "tot" for total dissipation) is $S_{d s \text { tot }} / S_{w l \text { tot }}=12.3 \times 10^{-6} / 4.3 \times 10^{-6} \approx 3$. In the frequency range below $2 f_{p}$ the swell dissipation is, however, a few orders of magnitude greater than the whitecapping dissipation term. Figure 2 demonstrates that the functional form of the swell dissipation used here is similar to the turbulent dissipation due to interaction with the air as postulated by Ardhuin et al. (2010).

\subsection{Duration-limited growth}

The duration-limited test is an idealized academic test of wave evolution for a single point in an infinite ocean under homogeneous wind-forcing with constant wind speed of $12 \mathrm{~m} \mathrm{~s}^{-1}$, constant direction and commencing from 
calm conditions. The duration of this test is limited to 12 hours of simulation with a time step of 30 seconds (15 seconds for source term integration). The spectral grid is discretized in 24 directions and 40 frequencies, logarithmically spaced between $f=0.042 \ldots 1.7 \mathrm{~Hz}$ with an increment $f_{n+1}=1.1 f_{n}$, where $f_{n}$ is the $n$-th frequency. The performance of the test is compared against existing physics: TC96, TEST451, and in some cases to WAM3, and WAM4+. In the TC96 model, stability correction and uncapped friction velocity from Tolman and Chalikov (1996) wind input were used.

495

Integral growth curves are usually the subject of scrutiny and tuning and generally all the commonly used source functions perform reasonably well with respect to the experimental dependences of non-dimensional energy $\varepsilon=\epsilon^{2} g^{2} U_{10}^{-4}$ as a function of non-dimensional peak frequency $\nu=f_{p} U_{10} g^{-1}$, where $\epsilon^{2}$ is the total variance. Figure 3 depicts (left panel) approximate nonlinear interactions, DIA and (right panel) exact nonlinear interactions, XNL. When normalised by the observational parameterization of Babanin and Soloviev (1998a) with respect to the $95 \%$ confidence intervals (shaded grey), the non-dimensional evolution of the BYDRZ source term is in fair agreement with the existing physics TC96, WAM3, and WAM4+. TEST451 source terms show excellent performance with respect to the empirical model for both DIA and XNL computations. Other source terms are higher at the peak but within the confidence intervals of the empirical model.

As waves develop traditional parameterizations keep injecting energy near the peak (Fig. $4 \mathrm{a}-\mathrm{d}$ ) and for TC96 the input $S_{\text {in }}$ keeps growing at the peak 510 frequency (Fig 4 a,b). The BYDRZ input behaves differently at the spectral peak. It is strong initially, but decays later as waves mature, which yields 
approximate two times lower input at the peak frequency at 4 hour and 8 hours of the simulation (Fig. 4 e,f). Beyond the peak the input energy decays with increasing frequency and the rate of decay is more rapid for TC96 source terms and slower for TEST451. The BYDRZ input is larger beyond the peak of the spectrum relative to TC96 and TEST451, which can be attributed to the behaviour of the saturation spectra $B_{n}$ given in equation (6). In the original input term $S_{i n}^{\text {DBYB }}$ formulated by Donelan et al. (2006), the high input beyond the peak is more pronounced as depicted in Figure 4 (bottom panels). The constraint (or limiter) applied to match the wave supported stress reduces some of the energy in the tail region of the Donelan et al. input (DBYB). The decay of the initial peak (around $0.2 \mathrm{~Hz}$ ) of the BYDRZ input (not shown) remains steady until after about 12 hours of simulation, a new peak is formed due to enhanced energy around between 0.3-0.6 Hz. Injecting more energy at high frequencies corresponds to a higher dissipation in the tail region which however does not necessarily follow the spectral shape of the input $S_{i n}$. The region after the peak of the BYDRZ input spectrum would follow the shape of the more traditional formulations depicted in Figure $4 \mathrm{a}-\mathrm{d}$ when the saturation spectra is replaced by the more conventional steepness $a k=2 \epsilon k$, where $\epsilon^{2}$ is the total surface variance (or total integral of the spectrum). In all parameterizations, the strong input at the peak is compensated by a strong dissipation $S_{d s}$ in which the magnitude of the peak of the dissipation responds to the magnitude of the input.

In WAVEWATCH the prognostic tail of the energy spectrum is usually 535 prescribed and typically proportional to $f^{-5}$ beyond a cut-off frequency. Figure 5 depicts the level of the spectral tail of the non-directional spectrum 
after 9 hours of simulation by means of (left) approximate and (right) exact non-linear interaction computation for different source term parameterizations. Figure 5 also shows the empirical model level of the tail based on

the Black Sea measurements of Babanin and Soloviev (1998a) with 95\% confidence intervals with respect to the peak frequency $f_{p}^{\text {TC96 }}=0.172 \mathrm{~Hz}$ as estimated in the TC96 simulation (DIA). Tolman and Krasnopolsky (2004) and Tolman (2013) showed that the over estimation of the spectral peak in TC96 can be attributed to the DIA which is consistent with Figure 5 (left panel). Estimates of peak frequency (DIA) for all other source terms differ: $f_{p}^{\text {WAM3 }}=0.163 \mathrm{~Hz}, f_{p}^{\text {WAM4 }+}=0.157 \mathrm{~Hz}, f_{p}^{\text {TEST451 }}=0.161 \mathrm{~Hz}$, and $f_{p}^{\text {BYDRZ }}=0.159 \mathrm{~Hz}$, for WAM3, WAM4 + , TEST451, and BYDRZ source terms, respectively. In Figure 5 the high frequency tail of TEST451 and BYDRZ source terms is free. These two parameterizations overestimate so the level of spectral tail in respect to the prescribed tails of TC96 and WAM4+ source term packages and for WAM3 the tail is proportional to frequency to the power -4.5 . WAM3 originally prescribes the prognostic part of the spectrum to the power -4 (WAMDI Group, 1988) but was modified to account for numerical stability in the dynamic integration scheme 55 (Tolman, 1992). Since XNL responds strongly to energy at high frequencies the BYDRZ parameterization shows spurious growth (Van Vledder, personal communication). To reduce spurious growth at high frequency plotted in Figure 5 (right panel), the cut-off frequency $f_{c}$ for the prognostic tail is set to 6 times the mean frequency $\langle f\rangle$ which typically is outside the range of the discrete frequency spectrum: $f_{c}=6\langle f\rangle$.

The growth rate in a duration-limited academic test depends on the wind 
speed selected, thus, the idealized test was repeated for winds in the range of $4-20 \mathrm{~m} \mathrm{~s}^{-1}$. The ensemble average growth rate for low winds $\left(4-10 \mathrm{~m} \mathrm{~s}^{-1}\right)$ and moderate to high winds $\left(11-20 \mathrm{~m} \mathrm{~s}^{-1}\right)$ is depicted in Figure 6. Here, growth 
estimated in the form of directional spread $\sigma_{\theta}$ after Kuik et al. (1988) for a wind speed of $12 \mathrm{~m} \mathrm{~s}^{-1}$. Kuik et al. (1988) calculated the directional spread from the total sea surface variance $\epsilon^{2}$ by integration up to the highest discrete measured wavenumber $k_{\max }$ :

$$
\begin{aligned}
a & =\int_{0}^{2 \pi} \int_{0}^{k_{\max }} \cos (\theta) F(k, \theta) d k d \theta \\
b & =\int_{0}^{2 \pi} \int_{0}^{k_{\max }} \sin (\theta) F(k, \theta) d k d \theta \\
\sigma_{\theta} & =\left(2-2\left(\frac{a^{2}+b^{2}}{\epsilon^{2}}\right)^{1 / 2}\right)^{1 / 2} .
\end{aligned}
$$

The BYDRZ results indicate that the width of the spectrum widens at the peak as the wave field matures. For young seas the width at the peak is consistent with observations (empirical dependence BS98; Babanin and Soloviev, 1998b; Hasselmann et al., 1985) but the decrease of the width parameter as waves develop was not achieved in the model. In Babanin et al. (2010) it was argued that in order to achieve this, proper observation-based directional distributions for source functions need to be introduced. At frequencies above the spectral peak up to $3 f_{p}$ the BYDRZ spectrum becomes much broader which is consistent with known behaviour of the approximate nonlinear interaction DIA (Figure 7, right panels). In the tail region this spectrum is comparable to the width calculated by other source terms. This effect can be attributed to the DIA since the full wave-wave interaction computation (XNL) corrects for most of the directional spread. From the two-dimensional non-linear source term (not shown) it is clear that the DIA transfers significant energy to frequencies above the spectral peak $\left(1 f_{p}-3 f_{p}\right)$. Comparisons against direction spreading measured by buoys in the global hindcast (section §3.5) confirm that the spreading is broader at frequencies 
above the spectral peak for the BYDRZ source terms (an example is given later in Figure 14). It is known that the DIA broadens the spectrum in both frequency and direction which becomes narrower when using XNL for non-linear wave-wave computations (eg. Rogers and van Vledder, 2013; Hasselmann et al., 1985, their Fig. 10, 12).

\subsection{Turning winds}

Observations for this type of test are rare and field campaigns are difficult to plan and execute. However, in the ocean the wind can turn rapidly and originate from any direction and therefore opposing winds can be expected to occur in at least some parts of the directional spectrum. An example is given later in $\S 3.5$ in Figure 14. This situation is also common under hurricane conditions and Young (2006, their Fig. 5d) showed the directional spectra for the left-rear quadrant of the storm where the difference between windsea and dominant swell was approximately $170^{\circ}$. The wave model has to deal with this type of situation and therefore an idealized test was selected to compare differences between selected source terms. The duration-limited test in $§ 3.2$ showed that the BYDRZ source terms grow faster in the earlier stages of wave development. When using exact non-linear wave-wave interaction computation and for $12 \mathrm{~m} \mathrm{~s}^{-1}$ wind, the BYDRZ input at the peak is higher compared to parameterizations TEST451 and TC96. At later stages of wave growth the effect is reversed and the input is much lower (see Fig. 4b,d,f). In order to test the contribution of the negative part of the input source term introduced in equation (10) the source terms were tested under the conditions of turning winds. For that, the duration-limited test with constant wind forcing of $12 \mathrm{~m} \mathrm{~s}^{-1}$ was modified so that the wind suddenly turns by $180^{\circ}$ 
after 6 hours. In this test the parameter for the negative input $a_{0}$ was set to 0.04 . In addition, the parameter for swell parameterisation $b_{1}$ is set to a

635 depicted earlier in Figure 1. In this academic test, the BYDRZ dissipation is the sum of whitecapping dissipation and swell dissipation.

The evolution of the input source term $S_{\text {in }}$ with time is divided in two phases where the turn of the wind marks the beginning of Phase II. In Phase 640 input features strong negative input at low frequencies when the wind turned; 
however, a new peak for the wind sea is quickly formed and the evolution of the input follows as described in Phase I.

Corresponding to the input source term, time evolution of the dissipation $S_{d s}$ is depicted in Figure 9. During Phase I, the peak of the dissipation source term corresponds to the peak of the input (Fig. 8). As observed for TC96 and TEST451 input, the rate of decay towards higher frequencies is proportional to the peak frequency which is more evident for TEST451. As waves develop, the dissipation at the peak increased in TC96 and TEST451 parameterizations. When the sea is young, the BYDRZ dissipation is stronger at the peak which decays with time. However, when waves mature, dissipation beyond the spectral peak grows but saturates quickly. Compared to TC96 and TEST451, the BYDRZ dissipation is high beyond the spectral peak to compensate the high input in the region below approximately $0.7 \mathrm{~Hz}$. This can be attributed to the highly nonlinear dissipation terms $T_{1}$ and $T_{2}$ with power 4. The TEST451 dissipation shows similar behaviour. As the wave field matures, the level of dissipation beyond the peak increases, however, without saturation. Although the evolution with time of the three models is similar, the TC96 dissipation is consistently low compared to TEST451 and BYDRZ. In transition from wind sea to swell (Phase II), dissipation is only prominent at low frequencies. Dissipation at the old peak decays with time; however, the rate of decay varies between the models. For example, at low frequencies the decay rate for BYDRZ dissipation is strongest, followed by TEST451 and TC96. 


\subsection{Slanting fetch}

The slanting fetch test was developed to test the directional response of the wave spectrum to asymmetrical boundaries (The SWAMP Group, 1985). The test consists of a square-box ocean with dimensions of exactly $1,000 \times 1,000 \mathrm{~km}$. The wave field is zero at the upwind boundary (lower left corner) and open at the downwind end. Slanting fetches were initialized from calm conditions and modeled for 48 hours using a constant wind speed of $12 \mathrm{~m} \mathrm{~s}^{-1}$ aligned with the 45 degree diagonal. The test was carried out with approximate (DIA) and exact nonlinear four-wave interactions (XNL).

Growth rates were compared by means of non-dimensional energy $\varepsilon$ and non-dimensional fetch $\chi=g x U_{10}^{-2}$, where $g$ is the gravitational acceleration and $x$ is the fetch. In the direction of the wind and along the diagonal (i.e. mean wave direction) the growth rate in all three models is reduced compared to orthogonal fetch growth curves because waves travelling at an angle experience reduced generation area in the dimension orthogonal to the wind. As a result, at the downwind end of the fetch wave growth is about $60 \%$ of wave growth obtained under orthogonal fetch geometry. The concept of effective fetch for which empirical models were derived (e.g. JONSWAP Hasselmann et al. (1973), Donelan et al. (1985), Dobson et al. 700 (1989), and CERC (1977)) do not hold under slanting fetch conditions depicted in Figure 10 (The SWAMP Group, 1985; Bottema and van Vledder, 2008). In contrast to the growth rate depicted in the duration-limited test (Fig. 6), the growth of non-dimensional energy in the case of the slanting fetch is lower for BYDRZ source terms. The range plotted in Figure 6 is for effective durations from 3 to 6 hours. For example, if one considers $12 \mathrm{~m} \mathrm{~s}^{-1}$ 
winds over the duration of 12 hours, the duration-limited growth converges with TES451 at non-dimensional times greater than $10^{4}$ (not shown). The equivalent duration (CERC, 1977; Young, 1999) for a fetch of $1000 \mathrm{~km}$ is about 34 hours. As a result the BYDRZ growth curve shown in Figure 10 are significantly stronger than TC96. Along the asymmetric boundary the mean wave direction (not shown) can significantly diverge from the wind direction which results in a skewed directional spectrum (Donelan et al., 1985; The SWAMP Group, 1985; Ardhuin et al., 2007). At the southern 715 upwind boundary at a fetch of $x=700 \mathrm{~km}$ and after 24 hours $(48 \mathrm{~h})$ of simulation the mean wave direction diverges from the direction of wind by $10^{\circ}\left(20^{\circ}\right)$ and at the peak the difference is about $20^{\circ}\left(30^{\circ}\right)$ which was found to be consistent between the three models.

\subsection{Global hindcast}

The global hindcast follows the operational wave model setup (Chen et al., 2004) and covers a $1.00^{\circ} \times 1.25^{\circ}$ latitude-longitude grid around the globe up to $78^{\circ}$ north/south in latitude. The resolution of the spectral grid from the operational model setup was increased and covers 36 directions and 35 frequencies logarithmically spaced with an increment of $10 \%(f=$ $0.0373-0.9529 \mathrm{~Hz}$ ). Field output is created every hour and co-located to individual altimeter tracks sourced from the calibrated altimeter database described in Zieger et al. (2009). The co-location procedure described in Rascle et al. (2008) is utilized. The Southern Ocean is frequently visited by icebergs that originate from Antarctica which is a potential source of 
et al. (2011b, version CEP05.2b) icebergs were treated as sub-grid obstacles allowed to change their location with time. In addition to sea ice, Climate Forecast System Reanalysis (CFSR) winds and currents (Saha et al., 2010) were utilized to drive the wave model for the year 2006, for which an optimal value for the non-dimensional swell dissipation parameter $b_{1}=0.250 \times 10^{-3}$ was found. This value was then cross-validated against years 2004, 2005, and 2013. Including currents in the model has two implications for the wave model: (i) a current-induced wavenumber shift and (ii) a relative reduction of wind input for the case of following currents. The wave model was compiled with the compile option for the current-based reduction of wind and a reduction coefficient of 0.5 was selected. Hersbach and Bidlot (2008) and Bidlot (2010, 2012a,b) investigated the effect of surface currents as boundary condition for the wind profile and noticed a reduction of absolute wind speed due to changes in the surface stresses and suggested a reduction by $50 \%$. A relative reduction in wind speed largely reduced the bias in the Southern Ocean, in which currents are following the winds for most of the time during the year. When compared against altimeter, there remains a strong gradients in mean wave height across the Pacific particularly when comparing high and low latitudes and eastern and western central Pacific (Bidlot, 2010, 2012a,b). Ardhuin et al. (2010, TEST441) noted that the model did not perform satisfactorily with a constant swell coefficient and proposed a dynamic value for the swell decay coefficient rather than a constant. Auxiliary online material from Ardhuin et al. (2009) contains estimates for swell dissipation rate $\mu$ and initial swell heights $H_{0}$ derived from synthetic aperture radar 755 data from in total 22 storms. Tabulated values for $\mu$ are not constant and 
were used to calculate the swell heights in the far field based on its observed initial swell height $H_{0}$ and at a distance of $x=\mathbf{c}_{\mathrm{g}} \Delta t=10,000 \mathrm{~km}$ using equation (25), hereafter labelled as $H_{s w l}^{A}$. For comparison, swell heights $H_{s w l}^{B}$ at the same distance were estimated with equation (24) but for values of $b_{1}$ that are consistent with the swell dissipation rate in the wave model. Figure 11 depicts the ratio of the swell height estimates as a function of measured dissipation rate $\mu$. If the swell height estimates match, they would coalesce with the 1.0 line on the vertical axis in the plot. In Figure 11 one can see that there exists a difference between the two estimates $H_{s w l}^{A}$ and $H_{s w l}^{B}$ due to the fact that $b_{1}$ is constant in $H_{s w l}^{B}$. Steep swells will be over-predicted in $H_{s w l}^{B}$ for small $b_{1}$ and this difference increases for larger values of $\mu$. However, this difference is not random and increases with steepness (wave height over wave length), which was visualized with scaling of marker size in the plot (e.g. a small marker means low steepness). The data replotted in Figure 11 (stars) suggest a proportionality of swell coefficient $b_{1}$ with steepness squared. Ghantous and Babanin (2014), however, found that such quadratic dependence produced too much mixing when included in a one-dimensional turbulence model (Umlauf and Burchard, 2005). In a similar fashion to Ghantous and Babanin (2014), but adding a linear dependence of steepness to coefficient $b_{1}$ in equation (23), yields improved results by means of mean bias in wave height compared to altimeters. The steepness dependent swell coefficient is given as:

$$
b_{1}=B_{1} \cdot 2 \epsilon k_{p}
$$

In equation (28), $B_{1}$ is a scaling coefficient, $\epsilon^{2}$ is the total sea surface 
variance and $k_{p}$ is the peak wavenumber. Table 1 lists coefficients used in all simulations and hindcasts.

Wave model tuning largely depends on the quality of the forcing field and winds from different operational centers typically show different characteristics when compared against independent satellite data. Here, independent refers to satellite data that is not assimilated in the reanalysis product (i.e. altimeters). For example, statistical analysis revealed that the bias for NOGAPS reanalysis winds (Hogan and Rosmond, 1991) for 2006 is about $0.85 \mathrm{~m} \mathrm{~s}^{-1}$ low compared to JASON1 wind estimates. In contrast CFSR winds (Saha et al., 2010) have a negative bias of $0.40 \mathrm{~m} \mathrm{~s}^{-1}$, that is reanalysis winds are low compared to observations. In any case both reanalysis fields have a high correlation (NOGAPS: 0.91 and CFSR: 0.93) with an overall root-mean-square (RMS) error of $1.8 \mathrm{~m} \mathrm{~s}^{-1}$ for NOGAPS and $1.5 \mathrm{~m} \mathrm{~s}^{-1}$ for CFSR which is slightly greater than the overall RMS error obtained from the altimeter calibration against NDBC buoys (RMS error: $1.28 \mathrm{~m} \mathrm{~s}^{-1}$; Zieger et al., 2009). This typically results in a set of coefficients for each wind forcing product based on the number of parameters of the source term when tuning the model. Using operational winds at National Centers for Environmental Prediction (NCEP), this procedure was adapted to optimize TC96 source terms (Tolman, 1998). One method to avoid this is to tune the wind input based on the forcing field used in the model run. Ardhuin et al. (2011a) and Rascle and Ardhuin (2013) listed different sets of values for the wind-wave growth parameter $\beta_{\max }$, a tunable parameter that allows adjustment to different wind fields. For example, a $\beta_{\text {max }}$-value of 1.52 is used for ECMWF winds. For CFSR winds the parameter is reduced to 
$\beta_{\max }=1.33$ (Ardhuin et al., 2011a). The period 2007-2010 shows persistent by means of a BLT diagram and in Figure 13 as scatter density plots. In addition, differences in the shape of the spectra are depicted in Figure 14 and Figure 15 (top panel). These figures show the TC96 source terms 
overestimate wave height (e.g. Fig. 12, Fig. 13, Fig 14) which is not surprising since no adjustment to the wind was performed and the source terms were optimized over the period 1994-1995 and re-validated in 2000 (Tolman, 2002; Chawla et al., 2013). Nevertheless, it is fair to say that TC96 performs well in this simulation in the Gulf of Mexico as shown for the West Tampa location in Figure 15 (top panel). When adjusted for wind, the TEST451 and BYDRZ source terms are fairly consistent in overall scatter statistics. The 2013 model run actually showed an RMS error of $0.35 \mathrm{~m}$ for both models TEST451 and BYDRZ. Again, scatter index (or relative error) and RMS error appear to be slightly superior in the TEST451 model. This is illustrated in the BLT diagram (Fig. 12) where all but the TC96 model (point 3) run show better statistics closer to the observations. Similar to this, the spatial bias between TEST451 and BYDRZ is depicted in Figure 16. Both parameterizations show a negative bias in the central western Pacific and as noted by Ardhuin et al. (2010) this might be due to the obstruction grid to mask islands which may eliminate shoreline reflection in a region where the ratio between shoreline to sea surface area is large. Nesting could potentially address this issue for which further work is required. In both cases, inclusion of icebergs and to a larger degree currents reduced the bias in the Southern Ocean, however the bias in the South Atlantic largely remains unresolved. Treatment of sea ice in the hindcast may be over-simplistic and may contribute to bias in the Southern Ocean. The bottom panel of Figure 16 shows the normalized RMS error (Ardhuin et al., 2010) for significant wave height which is similar to the TEST451 model, however, in the north Pacific and central east Pacific the normalized RMS error is a little lower in the 
TEST451 model.

855 Figure 5 suggested that the level of the spectral tail is high, outside the confidence intervals of BS98. This is however an idealized academic test. In a global model run the level of the tail is not significantly different from the observed spectrum as depicted in Figure 14 for an event in November 2006 (see figure caption for wave height estimates). The location shown in Figure 14 is dominated by swells propagating into the region and local windsea generated by easterly trade winds. Out of the three model runs the BYDRZ tail is highest but the difference from the observation is only visible for short waves with frequencies above $0.4 \mathrm{~Hz}$. Another difference between the source terms is the directional spreading of the locally generated waves depicted in Figure 14. The spreading is smallest for the TC96 parameterization and greater for BYDRZ source terms at about two times the peak frequency $(0.2 \mathrm{~Hz})$. The directional spread $\sigma_{\theta}(27)$ at about the peak frequency of the buoy $(0.14 \mathrm{~Hz})$ is fairly consistent between the source terms with $24^{\circ}$, $27^{\circ}$, and $28^{\circ} \mathrm{N}$ for TC96, TEST451, and BYDRZ respectively. Beyond the spectral peak, the spectrum is much broader and spreading increased to $31^{\circ}$, $37^{\circ}$, and $45^{\circ} \mathrm{N}$ for TC96, TEST451, and BYDRZ.

Results from Figure 7 and Figure 14 indicate that the DIA broadens the spectrum in the BYDRZ source term. This broadening is depicted in Figure 15 (bottom panel) for an observed spectrum in an event in February 2006 (see figure caption for wave height and mean wave direction estimates). Out of the three models, the spreading is smallest for TC96 parameterization and strongest for BYDRZ source terms. The directional spread $\sigma_{\theta}(27)$ at about the peak frequency of the buoy $(0.15 \mathrm{~Hz})$ is fairly consistent between 
the source terms with $15^{\circ}, 20^{\circ}$, and $28^{\circ} \mathrm{N}$ for TC96, TEST451, and BYDRZ (10\% increment), scaled between $f=0.06 \ldots 1.04 \mathrm{~Hz}$. Following the results from the global hindcast, the value for the negative input $a_{0}$ was set to 0.04 and the non-dimensional swell coefficient $b_{1}$ was set to 0.00025 . The 
performance of the presented source terms is compared against hourly records from in situ instrument NDBC buoy 45007 for which directional data is available.

The growth curves of total wave energy, an integral wave property, were tested in the academic test (Fig. 3 and 6). However, other mean wave parameters such as mean wave direction, and various wave periods $\left(T_{01}\right.$, $T_{02}$, and $\left.T_{-10}\right)$ all depend on the spectral moment following the form: $T_{i j} \propto$ $m_{i} / m_{j}$, where for $n=\{i, j\}, m_{n}$ is the $n^{\text {th }}$-order-moment of the spectrum defined as $m_{n}=\int f^{n} F(f) d f$ (Holthuijsen, 2007). Scatter statistics of integral wave parameters presented in Table 2 are almost identical to model-data comparison for TEST451. However, statistically, TEST451 is a little better than the source terms presented here. Results from Table 2 also indicate that the peak period is least well represented in the model, however, other mean periods like $T_{01}, T_{02}$, and $T_{-10}$ show good agreement. In contrast to the preliminary results in Zieger et al. (2011), the integral parameters are in excellent agreement with observations from NDBC buoy 45007. The improvement can be attributed to the negative wind input, an alternate formulation to estimate the surface stress, and the introduction of a cut-off frequency (i.e. $f_{\max }=0.4 \mathrm{~Hz}$ ) to match the frequency range used by NDBC buoys. In any case, results from the hindcast represent an improvement over the TC96 source terms in an environment dominated by young seas such as the Great Lakes. Tuning for the TC96 source terms was originally done for a global ocean-scale domain and therefore the performance in small-scale applications is not optimal (Tolman, 2002). Similar to the simulations of waves in hurricanes (see §3.7) bulk error statistics do not show that TC96 
systematically underestimates the peaks in the hindcast (Tolman et al., 2011; vortex hurricane wind field. The calibration procedure for the wind field is described in detail in Mason et al. (2007). The spatial grid is based on the NRL's 2 nautical miles resolution database (DBDB2) covering a 
domain from $98.0-80.0^{\circ} \mathrm{W}$ and $18.0-30.8^{\circ} \mathrm{N}$. The spectral discretization is

set to $10^{\circ}$ directional resolution and logarithmically spaced frequencies in the range $0.038-0.971 \mathrm{~Hz}$ with an increment of $10 \%$. The simulation was carried out from 25-30 August 2005 with parameterizations TC96, TEST451, and BYDRZ and compared against NDBC buoy 42040 depicted in Figure 17. The TC96 hindcast was performed with stability correction and capped friction velocity computation. Parameterizations TEST451 and BYDRZ give reasonable results, close to the observations, however BYDRZ wave height is slightly greater than waves estimated with TEST451 model. This can be explained due to the stronger growth rates in the BYDRZ parameterization especially for younger waves. For the first part of the simulation, TC96 parameterization is in agreement with the observation, however, the model underestimates waves greater than $3 \mathrm{~m}$ (after 15 September 2006). When looking at scatter statistics for NDBC buoy 42040 all three models show excellent correlation at $\rho \approx 97 \%$. With a bias of $-0.03 \mathrm{~m}$ (Fig. 17), the BYDRZ model is close to the observations, where as TEST451 is $0.31 \mathrm{~m}$ low and TC96 is $0.57 \mathrm{~m}$ low. A regression line forced through zero has a slope of $1.03(0.97 \mathrm{~m})$ for BYDRZ, $0.96(0.91 \mathrm{~m})$ for TEST451 and $0.86(1.14 \mathrm{~m})$ for TC96 with overall RMS error given in round brackets. The overall RMS error is within $5.4 \%$ of maximum observed wave height for TEST451 source terms. For BYDRZ and TC96 simulation the relative RMS error is 5.7\% and $6.7 \%$, respectively. The bulk statistics do not indicate that the TC96 model consistently underestimates the peaks in hurricanes (Tolman and Alves, 2005; Chao and Tolman, 2010). One large difference between the source terms is in mean period $T_{02}$, depicted in Figure 17 (bottom panel) on 27 August 2005 
(12 $\mathrm{h} \mathrm{UTC).} \mathrm{The} \mathrm{directional} \mathrm{spectrum} \mathrm{(not} \mathrm{shown)} \mathrm{indicates} \mathrm{the} \mathrm{arrival} \mathrm{of} \mathrm{a}$

$a k$. If the saturation spectrum is replaced by the more conventional form of $a k=2 \epsilon k$, where $\epsilon^{2}$ is the total sea surface variance, then the input would 
decay faster beyond the spectral peak. This is because the conventional form is based on an integral parameter and therefore makes the wind input

1005 require recalibration of the input parameterization and the dissipation to balance the input.

To satisfy the constraint (12) to match the total stress empirical relations (13) - (14) are used. To compare this approach to the work of others, stresses 1010 of wave development the empirical spectra JONSWAP (Hasselmann et al., $1973)$ is applied. Figure 18 shows the normalized stress as ratio of waveinduced stress (15) to total stress (12) for a range of wave ages $c_{p} / u_{\star}=$ $[4,19]$. Data in Figure 18 was averaged by groups of wave age (natural numbers) and error bars show the variance of relative stress for each group. The empirical formulation J89 has a much stronger dependence on wave age which indicates that the wave induced stress is much higher for a young sea state. For young waves $\left(c_{p} / u_{\star}<7\right)$, this behaviour is partially reproduced by the Miles-Janssen-type of input (WAM4+ and TEST451) where influence of wave-supported stress reduces as the waves grow. Moreover, for waves with wave age $7<c_{p} / u_{\star} \leq 17$ with the Miles-Janssen type of input, there appears to be a linear growth and beyond after the wave supported stress drops. On the other hand, the constraint used in the BYDRZ input yields an increase in wave stress but saturates at a wave age of $11<c_{p} / u_{\star}$. The variability in normalized wave stress in BYDDRZ is less than in WAM4+ and TEST451. The TC96 source terms has similar characteristics to the Miles-Jansen-type of input but the level of the wave stress is significantly lower in comparison. 
Idealized academic test showed that growth rates for TC96 is different compared to TEST451 and BYDRZ source terms. It has been demonstrated between TEST451 and BYDRZ is that in the BYDRZ parameterization of 
swell, consists of two components: (i) negative wind input and (ii) by interactions of waves with isotropic turbulence with variable dissipation coefficient $b_{1}$ based on steepness. This makes the swell dissipation function comparable to TEST451 directional swell parameterization. In the global hindcast the negative input $a_{0}$ and swell scaling coefficient $B_{1}$ have been balanced to yield lowest overall RMS errors. Retuning the negative input $a_{0}$ will dissipate waves over the entire range of wave heights. In contrast $B_{1}\left(\right.$ or $\left.b_{1}\right)$ dominantly dampens waves in order of greater than $6 \mathrm{~m}$.

In Tolman and Chalikov (1996) source terms the calculation of cut-off frequency for the prognostic tail is based on the peak of the wind input and the surface stress is based on the windsea part of the spectrum using a parametric relation. This is similar to the approach presented here, where a constraint is applied to the wind input using the parameterization of the wave-induced stress, Eq. (15). In the current implementation, a cut-off frequency $f_{c}$ for the prognostic tail $f^{-5}$ is imposed at high frequency. To prevent instabilities at the highest frequencies in the exact non-linear fourwave interactions, the cut-off frequency is defined as six times the mean frequency.

The idealized duration-limited test also revealed that the BYDRZ source terms produce a directionally broader spectrum. The width at the peak is governed by non-linear interaction which depends on the directional distribution of input and dissipation at the tail. The dissipation function used in this parameterization is isotropic. Nevertheless, there exist experimental evidence that when waves break the directional spectrum narrows (Young and Babanin, 2006) and Babanin et al. (2010) investigated directional distri- 
butions for the dissipation function. However, this is open to further research. The directional distribution of both input and dissipation are unknown.

1080

\section{Conclusion}

This paper describes the parameterization of the observation-based source terms implemented in the third generation wave model WAVEWATCH. The new model has been tested in a range of idealized academic tests as well as real simulations in the form of global hindcast and under conditions of extreme winds. The cost of running various different source terms in WAVEWATCH is tabulated in Table 3. Although a number of features have been added to the source term it is slightly faster to run compared to its predecessor TC96. Even though the new model is based on observations, our knowledge on the deep water source terms and processes involved in the generation of wind waves is not yet fully understood with some of the processes still being uncertain and open to various theories. At this stage, the key findings are as follows.

- The BYDRZ source term yields faster wave growth for young seas compared to TC96 and TEST451 source terms.

- As the wave field develops, the value of the wind input term near the spectral peak reduces (see Figure 4).

- Compared to TC96 and TEST451, input and dissipation is stronger at high frequencies for BYDRZ source term. 
- The overall strength of TEST451 and BYDRZ input and dissipation are significantly stronger than that of TC96 (see cases of slanting fetch and turning winds in Figures 8-10).

- The level of spectral tail is slightly high when plotted against observationbased parameterization BS98 (see Figure 5). The parameterization uses a free tail up to a cut-off frequency of six times the mean frequency.

- Figure 7 (and partially Figure 15) shows that BYDRZ input produces a broader directional distribution of the wave spectrum at the peak particularly when using DIA. The results from exact nonlinear wave-wave interactions (XNL) show such effect for mature waves only $\left(U_{10} / c_{p}<2.0\right)$

- Any potential bias in the wind field can be bulk adjusted by just comparing the winds and scaling the value for the drag coefficient, which is tunable via namelist parameter in the model.

- An optimal swell dissipation coefficient is found using the 2006 global hindcast $\left(a_{0}=0.09\right.$ and $\left.B_{1}=0.032\right)$.

\section{Acknowledgments}

The authors acknowledge funding from the U.S. Office of Naval Research through Naval Research Grant N00014-101-0418 and through funding from Woodside Energy Ltd. The authors gratefully acknowledge support from Department of Marine Sciences of the University of Southern Mississippi, MS, United States. The use of computing resources from the NeCTAR Research Cloud, an Australian Government project is highly appreciated. 
For extended discussion we like to thank Mostafa Bakhoday Paskyabi of the University of Bergen, Norway. The authors are thankful for all comments and criticism raised by four independent reviewers. Buoy data was sourced from Data Systems (DODS) server.

\section{Appendix A. Statistics for model validation}

Model and data comparison presented here uses a number of different conventional parameters. This appendix lists integral parameters and statistics used to quantify the skill of the model. Note that, lower and upper bounds are implied in the integration.

Integral parameters are defined as follows.

- Total sea surface variance $\epsilon^{2}=\iint F(f, \theta) d \theta d f$

- Wave height $\mathrm{H}_{\mathrm{s}}=4 \epsilon=4\left(\iint F(f, \theta) d \theta d f\right)^{0.5}$

1135

- Mean wave direction $\langle\theta\rangle=\arctan \left(\frac{\iint \sin (\theta) F(f, \theta) d \theta d f}{\iint \cos (\theta) F(f, \theta) d \theta d f}\right)$

- Peak period $\mathrm{T}_{\mathrm{p}}=f_{p}^{-1}$, where the peak frequency is calculated from the one-dimensional wave spectrum using a parabolic fit around the discrete peak.

- Mean period $\mathrm{T}_{01}=\epsilon^{2} /\left(\iint f F(f, \theta) d \theta d f\right)$

1140

- Mean period $\mathrm{T}_{02}=\left(\epsilon^{2} /\left(\iint f^{2} F(f, \theta) d \theta d f\right)\right)^{0.5}$

- Mean period $\mathrm{T}_{-10}=\left(\iint f^{-1} F(f, \theta) d \theta d f\right) / \epsilon^{2}$ 
For comparisons between model $\mathbf{M}$ and observations $\mathbf{O}$ with size of $n$ valid data pairs we utilized the following error statistics.

- Pierson's correlation $\rho=\operatorname{cov}(\mathbf{M}, \mathbf{O}) \operatorname{cov}^{-0.5}(\mathbf{M}) \operatorname{cov}^{-0.5}(\mathbf{O})$, where cov is the covariance between the two variables.

- Root-mean-square error e $=\left(\frac{1}{n} \sum(\mathbf{M}-\mathbf{O})^{2}\right)^{0.5}$

- $\operatorname{Bias} \mathrm{b}=\frac{1}{n} \sum(\mathbf{M}-\mathbf{O})$

- Scatter index $\mathrm{SI}=\left(\frac{1}{n} \sum(\mathbf{M}-\mathrm{O}-\mathrm{b})^{2}\right)^{0.5}\left(\frac{1}{n} \sum \mathbf{O}\right)^{-1}$

- normalized root-mean-square error nrmse $=\sum(\mathbf{M}-\mathbf{O})^{2}\left(\sum \mathbf{O}\right)^{-1}$

\section{References}

Alves, J.H.G.M., 2006. Numerical modeling of ocean swell contributions to the global wind-wave climate. Ocean Mod. 11, 98-122. doi:10.1016/j.ocemod.2004.11.007.

Alves, J.H.G.M., Chawla, A., Tolman, H.L., Schwa, D.J., Lang, G., Mann, G., 2011. The Great Lakes wave model at NOAA/NCEP: challenges and future developments, in: Proc. 12th Int. Workshop on Wave Hindcasting and Forecasting, Kohala Coast, HI, 30 Oct -4 Nov, 6pp.

Alves, J.H.G.M., Chawla, A., Tolman, H.L., Schwab, D., Lang, G., Mann, G., 2014. The operational implementation of a great lakes wave doi:10.1175/WAF-D-12-00049.1. 
Ardhuin, F., Chapron, B., Collard, F., 2009. Observation of swell dissipation across oceans. Geophys. Res. Lett. 36, L06607, 5pp. doi:10.1029/2008GL037030.

1165

1170

Ardhuin, F., Hanafin, J., Quilfen, Y., Chapron, B., Queffeulou, P., Obrebski, M., Sienkiewicz, J., Vandermark, D., 2011a. Calibration of the IOWAGA global wave hindcast (1991-2011) using ECMWF and CFSR winds, in: Proc. 12th Int. Workshop on Wave Hindcasting and Forecasting, Kohala Coast, HI, 30 Oct - 4 Nov, 13pp.

Ardhuin, F., Herbers, T.H.C., Watts, K.P., van Vledder, G.P., Jensen, R., Graber, H.C., 2007. Swell and slanting-fetch effects on wind wave growth. J. Phys. Oceanogr. 37, 908-931. doi:10.1175/JPO3039.1.

Ardhuin, F., Jenkins, A.D., 2006. On the interaction of waves and upper ocean turbulence. J. Phys. Oceanogr. 36, 551-557. doi:10.1175/JPO2862.1.

Ardhuin, F., Rogers, E., Babanin, A.V., Filipot, J.F., Magne, R., Roland, A., Van der Westhuysen, A., Queffeulou, P., Lefevre, J.M., Aouf, L., Collard, F., 2010. Semiempirical dissipation source functions for ocean waves. Part I: Definition, calibration, and validation. J. Phys. Oceanogr. 40, 1917-1941. doi:10.1175/2010JPO4324.1.

Ardhuin, F., Tournadre, J., Queffeulou, P., Girard-Ardhuin, F., Collard, F., 2011b. Observation and parameterization of small icebergs: Drifting breakwaters in the southern ocean. Ocean Model. 39, 405-410. doi:10.1016/j.ocemod.2011.03.004. 
Babanin, A.V., 2006. On a wave-induced turbulence and a 1185 wave-mixed upper ocean layer. Geophys. Res. Lett. 33, L20605, 6pp. doi:10.1029/2006GL027308.

Babanin, A.V., 2009. Breaking of ocean surface waves. Acta Phys. Slovaca 59, 305-535. URL: http://hdl.handle.net/1959.3/64445.

Babanin, A.V., 2011. Breaking and Dissipation of Ocean Surface Waves. $1190 \quad$ Cambridge University Press.

Babanin, A.V., 2012. Swell attenuation due to wave-induced turbulence, in: Proc. of the 31st Int. Conf. Ocean, Offshore and Arctic Engineering OMAE 2012, Rio de Janeiro, Brazil, 10-15 June 2011.

Babanin, A.V., Banner, M.L., Young, I.R., Donelan, M.A., 2007a. Wavefollower field measurements of the wind-input spectral function. Part III: Parameterization of the wind-input enhancement due to wave breaking. J. Phys. Oceanogr. 37, 2764-2775. doi:10.1175/2007JPO3757.1.

Babanin, A.V., Chalikov, D., 2012. Numerical investigation of turbulence generation in non-breaking potential waves. J. Geophys. Res. 117, C06010, 14pp. doi:10.1029/2012JC007929.

Babanin, A.V., Haus, B.K., 2009. On the existence of water turbulence induced by nonbreaking surface waves. J. Phys. Oceanogr. 39, 2675-2679. doi:10.1175/2009JPO4202.1.

Babanin, A.V., Soloviev, Y.P., 1987. Parameterization of width of directional 1205 energy distributions of wind-generated waves at limited fetches. Izvestiya Atmos. Ocean Phys. 23, 645-651. 
Babanin, A.V., Soloviev, Y.P., 1998a. Field investigation of transformation of the wind wave frequency spectrum with fetch and the stage of development. J. Phys. Oceanogr. 28, 563-576. doi:10.1175/1520-0485(1998)028<0563:FIOTOT >2.0.CO;2.

Babanin, A.V., Soloviev, Y.P., 1998b. Variability of directional spectra of wind-generated waves, studied by means of wave staff arrays. Mar. Freshwater Res. 49, 89-101. doi:10.1071/MF96126.

Babanin, A.V., Tsagareli, K.N., Young, I.R., D. Walker, D.J., 2007b. 1215 Implementation of new experimental input/dissipation terms for modeling spectral evolution of wind waves, in: Proc. 10th Int. Workshop on Wave Hindcasting and Forecasting, Oahu, HI, 11-16 November, 12pp.

Babanin, A.V., Tsagareli, K.N., Young, I.R., Walker, D.J., 2010. Numerical investigation of spectral evolution of wind waves. Part II: Dissipation term and evolution tests. J. Phys. Oceanogr. 40, 667-683. doi:10.1175/2009JPO4370.1.

Babanin, A.V., Van der Westhuysen, A.J., 2008. Physics of "saturationbased" dissipation functions proposed for wave forecast models. J. Phys. Oceanogr. 38, 1831-1841. doi:10.1175/2007JPO3874.1.

Babanin, A.V., Young, I.R., 2005. Two-phase behaviour of the spectral dissipation of wind waves, in: Proc. Fifth Int. Symp. Ocean Waves Measurement and Analysis, Madrid, Spain, 3-7 July, 11pp. 
Babanin, A.V., Young, I.R., Banner, M.L., 2001. Breaking probabilities for dominant surface waves on water of finite constant depth. J. Geophys. Res. 106, 11659-11676. doi:10.1029/2000JC000215.

Banner, M.L., Babanin, A.V., Young, I.R., 2000. Breaking probability for dominant waves on the sea surface. J. Phys. Oceanogr. 30, 3145-3160. doi:10.1175/1520-0485(2000)030<3145:BPFDWO >2.0.CO;2.

Banner, M.L., Gemmrich, J.R., Farmer, D.M., 2002. Multiscale measurements of ocean wave breaking probability. J. Phys. Oceanogr. 32, 3364-3375. doi:10.1175/1520-0485(2002)032<3364:MMOOWB >2.0.CO;2.

Banner, M.L., Peirson, W.L., 1998. Tangential stress beneath wind-driven air-water interfaces. J. Fluid. Mech. 364, 115-145. doi:10.1017/S0022112098001128.

Benilov, A.Y., 2012. On the turbulence generated by the potential surface waves. J. Geophys. Res. 117, C00J30, 12pp. doi:10.1029/2012JC007948.

Bidlot, J.R., 2010. Use of MERCATOR surface currents in the ECMWF forecasting system. ECMWF Technical Memoranda R60.9/JB/10104. European Centre for Medium-Range Weather Forecasts.

Bidlot, J.R., 2012a. Present status of wave forecasting at ECMWF, in: Proc. ECMWF Workshop on Ocean Waves, Reading, UK, 25-27 June.

Bidlot, J.R., 2012b. Use of MERCATOR surface currents in the ECMWF forecasting system, a follow-up study. ECMWF Technical Memoranda R60.9/JB/1228. European Centre for Medium-Range Weather Forecasts. 

wave dissipation and its model impact. ECMWF Technical Memoranda 509. European Centre for Medium-Range Weather Forecasts.

Boer, G.J., Lambert, S.J., 2001. Second-order space-time climate difference statistics. Clim. Dynam. 17, 213-218. doi:10.1007/PL00013735.

Booij, N., Ris, R.C., Holthuijsen, L.H., 1999. A third-generation wave model for coastal regions 1. model description and validation. J. Geophys. Res. 104, 7649-7666. doi:10.1029/98JC02622.

Bottema, M., van Vledder, G., 2008. Effective fetch and non-linear four-wave interactions during wave growth in slanting fetch conditions. Coast. Eng. 55, 261-275. doi:10.1016/j.coastaleng.2007.11.001.

Bowden, K.F., 1950. The effects of eddy viscosity on ocean waves. Phil. Mag. 41, 907-917. doi:10.1080/14786445008561023.

CERC, 1977. Shore protection manual. U.S. Army Coastal Research Center. Vols. 1-3.

CERC, 1984. Shore protection manual. U.S. Army Coastal Research Center. Vols. 1-2.

Chalikov, D.V., Makin, V.K., 1991. Models of the wave boundary layer. Bound.-Layer Meteorol. 56, 83-99. doi:10.1007/BF00119963.

Chao, Y.Y., Tolman, H.L., 2010. Performance of ncep regional wave models in predicting peak sea states during the 2005 north atlantic hurricane season. Wea. Forecasting 25, 1543-1567. doi:10.1175/2010WAF2222309.1. 
Chawla, A., Spindler, D.M., Tolman, H.L., 2013. Validation of a thirty year wave hindcast using the Climate Forecast System Reanalysis winds. Ocean Model. 70, 189-206. doi:10.1016/j.ocemod.2012.07.005.

1275

1280

Donelan, M.A., Babanin, A.V., Young, I.R., Banner, M.L., 2006. Wavefollower field measurements of the wind-input spectral function. Part II: Parameterization of the wind input. J. Phys. Oceanogr. 36, 1672-1689. doi:10.1175/JPO2933.1. 
Donelan, M.A., Babanin, A.V., Young, I.R., Banner, M.L., McCormick, C., 2005. Wave-follower field measurements of the wind-input spectral function. Part I: Measurements and calibrations. J. Atmos. Ocean. Tech. 22, 1672-1689. doi:10.1175/JTECH1725.1.

Donelan, M.A., Hamilton, J., Hui, W.H., 1985. Directional spectra of windgenerated ocean waves. Phil. Trans. R. Soc. Lond. A 315, 509-562. URL: http://www . jstor .org/stable/37696.

Durrant, T.H., Greenslade, D.J.M., Simmonds, I., 2013. The effect of statistical wind corrections on global wave forecasts. Ocean Model. 70, 116-131. doi:10.1016/j.ocemod.2012.10.006.

Durrant, T.H., Greenslade, D.J.M., Simmonds, I., Woodcock, F., 2014. Correcting marine surface winds simulated in atmospheric models using spatially and temporally varying linear regression. Wea. Forecasting 29, 305-330. doi:10.1175/WAF-D-12-00101.1.

Ewans, K.C., Kibblewhite, A.C., 1990. An examination of fetch-limited wave growth off the west coast of New Zealand by a comparison with the JONSWAP results. J. Phys. Oceanogr. 20, 1278-1296. doi:10.1175/1520-0485(1990)020<1278:AEOFLW>2.0.CO;2.

Filipot, J.F., Ardhuin, F., 2012. A unified spectral parameterization for wave breaking: From the deep ocean to the surf zone. J. Geophys. Res. 117, C00J08, 19 pp. doi:10.1029/2011JC007784. 
Gelci, R., Cazalé, H., Vassal, J., 1957. Prevision de la houle. la méthode des densités spectroangulaires. Bulletin d'Information du Commité Central Océanographie et d'Étude des Côtes 9, 416-435.

Ghantous, M., Babanin, A.V., 2014. One-dimensional modelling of upper ocean mixing by turbulence due to wave orbital motion. Nonlin. Processes Geophys. 21, 325-338. doi:10.5194/npg-21-325-2014.

Hasselmann, K., Barnett, T., Bouws, E., Carlson, H., Cartwright, D., Enke, K., Ewing, J., Gienapp, H., Hasselmann, D., Kruseman, P., Meerburg, A., Muller, P., Olbers, D., Richter, K., Sell, W., , Walden, H., 1973. Measurements of wind-wave growth and swell decay during the Joint North Sea Wave Project (JONSWAP). Dtsch. Hydrogh. Z. Suppl. A8, 95pp.

Hasselmann, S., Hasselmann, K., Allender, J.H., Barnett, T.P., 1985. Computations and parameterizations of the nonlinear energy transfer in a gravity-wave specturm. Part II: Parameterizations of the nonlinear energy transfer for application in wave models. J. Phys. Oceanogr. 15, 1378-1391. doi:10.1175/1520-0485(1985)015<1378:CAPOTN>2.0.CO;2.

Hersbach, H., Bidlot, J.R., 2008. The relevance of ocean surface current in the ECMWF analysis and forecast system, in: Proc. ECMWF Workshop on Atmosphere-Ocean Interaction, Reading, UK, 10-12 November.

Hogan, T.F., Rosmond, T.E., 1991. The description of the U.S. Navy operational global atmospheric prediction system's spectral forecast models. Mon. Weather Rev. 119, 1786-1815. doi:10.1175/15200493(1991)119<1786:TDOTNO>2.0.CO;2. 
Holland, G.J., 1980. An analytical model of the wind and pressure profiles

1340

in hurricanes. Mon. Weather Rev. 108, 1212-1218. doi:10.1175/15200493(1980)108<1212:AAMOTW>2.0.CO;2.

Holthuijsen, L.H., 2007. Waves in Oceanic and Coastal Waters. Cambridge University Press.

Holthuijsen, L.H., Powell, M.D., Pietrzak, J.D., 2012. Wind and waves in extreme hurricanes. J. Geophys. Res. 117, C09003, 15pp. doi:10.1029/2012JC007983.

Hwang, P.A., 2011. A note on the ocean surface roughness spectrum. J. Atmos. Ocean. Tech. 28, 436-443. doi:10.1175/2010JTECHO812.1.

Hwang, P.A., Wang, D.W., 2001. Directional distributions and mean square slopes in the equilibrium and saturation ranges of the wave spectrum. J. Phys. Oceanogr. 31, 1346-1360. doi:10.1175/15200485(2001)031<1346:DDAMSS>2.0.CO;2.

Janssen, P.A.E.M., 1989. Wave-induced stress and the drag of air flow over sea waves. J. Phys. Oceanogr. 19, 745-754. doi:10.1175/1520-0485(1989)019<0745:WISATD>2.0.CO;2.

Janssen, P.A.E.M., 1991. Quasi-linear theory of wind-wave generation applied to wave forecasting. J. Phys. Oceanogr. 21, 1631-1642. doi:10.1175/1520-0485(1991)021<1631:QLTOWW>2.0.CO;2.

Komen, G.J., Cavaleri, L., Donelan, M., Hasselmann, K., Janssen, P.A.E.M., 1994. Dynamics and Modelling of Ocean Waves. Cambridge University Press. 
Komen, G.J., Hasselmann, S., Hasselmann, K., 1984. On the existence of a fully developed wind-sea spectrum. J. Phys. Oceanogr. 14, 1271-1285. doi:10.1175/1520-0485(1984)014<1271:OTEOAF >2.0.CO;2.

Longuet-Higgins, M.S., Stewart, R.W., 1962. Radiation stress and mass transport in gravity waves, with application to 'surf beats'. J. Fluid. Mech. 13, 481-504. doi:10.1017/S0022112062000877.

Mason, L.B., Hardy, T., Bode, L., Astorquia, A., 2007. North Western Australia "10-4 Waves" Study Cyclone Track, Wind and Wave Modelling 
Methodology and Results. Industry Report. Woodside Energy Ltd., WA,

Reul, N., Branger, H., Giobanangeli, J.P., 1999. Air flow separation over unsteady breaking waves. Phys. Fluid. 11, 1959-1961. doi:10.1063/1.870058.

Rogers, W.E., Babanin, A.V., Wang, D.W., 2012. Observation-consistent 1405

Phillips, O.M., 1984. On the response of short ocean wave components at a fixed wavenumber to ocean current variations. J. Phys. Oceanogr. 14, 1425-1433. doi:10.1175/1520-0485(1984)014<1425:OTROSO>2.0.CO;2.

Pierson, W.J., Moskowitz, L., 1964. A proposed spectral form for fully developed wind seas based on the similarity theory of S. A. Kitaigorodskii. J. Geophys. Res. 69, 5181-5190. doi:10.1029/JZ069i024p05181.

Rascle, N., Ardhuin, F., 2013. A global wave parameter database for geophysical applications. Part 2: Model validation with improved source term parameterization. Ocean Model. 70, 174-188. doi:10.1016/j.ocemod.2012.12.001.

Rascle, N., Ardhuin, F., Queffeulou, P., Croizé-Fillon, D., 2008. A global wave parameter database for geophysical applications. Part 1: Wave-current-turbulence interaction parameters for the open ocean based on traditional parameterizations. Ocean Model. 25, 154-171. doi:10.1016/j.ocemod.2008.07.006.

input and whitecapping-dissipation in a model for wind-generated surface 
waves: Description and simple calculations. J. Atmos. Ocean. Tech. 29, 1329-1346. doi:10.1175/JTECH-D-11-00092.1.

Rogers, W.E., van Vledder, G.P., 2013. Frequency width in predictions of windsea spectra and the role of the nonlinear solver. Ocean Model. 70, 52-61. doi:10.1016/j.ocemod.2012.11.010.

Rogers, W.E., Wang, D.W.C., 2007. Directional validation of wave predictions. J. Atmos. Ocean. Tech. 24, 504-520. doi:10.1175/JTECH1990.1.

Saha, S., Moorthi, S., Pan, H.L., Wu, X., Wang, J., Nadiga, S., Tripp, P., Kistler, R., Woollen, J., Behringer, D., Liu, H., Stokes, D., Grumbine, R., Gayno, G., Wang, J., Hou, Y.T., Chuang, H.Y., Juang, H.M.H., Sela, J., Iredell, M., Treadon, R., Kleist, D., Delst, P.V., Keyser, D., Derber, J., Ek, M., Meng, J., Wei, H., Yang, R., Lord, S., Dool, H.V.D., Kumar, A., Wang, W., Long, C., Chelliah, M., Xue, Y., Huang, B., Schemm, J.K., Ebisuzaki, W., Lin, R., Xie, P., Chen, M., Zhou, S., Higgins, W., Zou, C.Z., Liu, Q., Chen, Y., Han, Y., Cucurull, L., Reynolds, R.W., Rutledge, G., , Goldberg, M., 2010. The NCEP Climate Forecast System Reanalysis. Bull. Amer. Meteor. Soc. 91, 1015-1057. doi:10.1175/2010BAMS3001.1.

Sanders, J.W., 1976. A growth-stage scaling model for the wind-driven sea. Dtsch. Hydrogh. Z. 29, 136-161. doi:10.1007/BF02227029. measurements of atmospheric pressure fluctuations above surface gravity waves. J. Fluid. Mech. 102, 1-59. doi:10.1017/S0022112081002528. 
Taylor, K.E., 2001. Summarizing multiple aspects of model performance in a single diagram. J. Geophys. Res. Atmos. 106, 7183-7192. 1430 doi:10.1029/2000JD900719.

Teixeira, M.A.C., Belcher, S.E., 2002. On the distortion of turbulence by a progressive surface wave. J. Fluid Mech. 458, 229-267. doi:10.1017/S0022112002007838.

The SWAMP Group, 1985. Ocean wave modelling. Plenum Press.

1435 Tolman, H., Alves, J.H.G.M., 2005. Numerical modeling of wind waves generated by tropical cyclones using moving grids. Ocean Model. 9, 305-323. doi:10.1016/j.ocemod.2004.09.003.

Tolman, H.L., 1990. The influence of unsteady depths and currents of tides on wind-wave propagation in shelf seas. J. Phys. Oceanogr. 20, 1166-1174. doi:10.1175/1520-0485(1990)020<1166:TIOUDA>2.0.CO;2.

Tolman, H.L., 1992. Effects of numerics on the physics in a third-generation wind-wave model. J. Phys. Oceanogr. 22, 1095-1111. doi:10.1175/15200485(1992)022<1095:EONOTP>2.0.CO;2.

Tolman, H.L., 1998. Validation of nceps ocean winds for the use in wind 1445 wave models. Global Atmos. Ocean Sys. 6, 243-268.

Tolman, H.L., 2002. Validation of WAVEWATCH III version 1.15. NOAA Tech. note 213. Envtl. Modelling Center. Camp Springs, MD. 
Tolman, H.L., 2013. A generalized multiple discrete interaction approximation for resonant four-wave interactions in wind wave models. Ocean Model. 70, 11-24. doi:10.1016/j.ocemod.2013.02.005.

Tolman, H.L., Banner, M., Kaihatu, J., 2011. The NOPP operational wave model improvement project, in: Proc. 12th Int. Workshop on Wave Hindcasting and Forecasting, Kohala Coast, HI, 30 Oct - 4 Nov, 19pp.

Tolman, H.L., Banner, M., Kaihatu, J., 2013. The NOPP 1455 operational wave model improvement project. Ocean Model. 70, 2-10. doi:10.1016/j.ocemod.2012.11.011.

Tolman, H.L., Chalikov, D., 1996. Source terms in a third-generation wind wave model. J. Phys. Oceanogr. 26, 2497-2518. doi:10.1175/15200485(1996)026<2497:STIATG>2.0.CO;2.

Tolman, H.L., Krasnopolsky, V.M., 2004. Nonlinear interactions in practical wind wave models, in: Eighth International Workshop on Wave Hindcasting and Forecasting. JCOMM Tech. Rep. 29, WMO/TD-No. 1319, Paper E1.

Tolman, H.L., the WAVEWATCH Dev. Group, 2014. User manual and 1465 system documentation of WAVEWATCH IIIß version 4.18. Tech. note MMAB Contribution No. 316. National Centers for Environmental Prediction. College Park, MD.

Tracy, B., Resio, D.T., 1982. Theory and calculations of the nonlinear energy transfer between sea waves in deep water. WES Rep. 11. US Army Corps 1470 of Engineers. 
Tsagareli, K., 2009. Numerical investigation of wind input and spectral dissipation in evolution of wind waves. Ph.D. thesis. University of Adelaide, School of Civil, Environmental and Mining Engineering. Available online at http://hdl.handle.net/2440/57907.

Tsagareli, K.N., Babanin, A.V., Walker, D.J., Young, I.R., 2010. Numerical investigation of spectral evolution of wind waves. Part I: Wind-input source function. J. Phys. Oceanogr. 40, 656-666. doi:10.1175/2009JPO4345.1.

Umlauf, L., Burchard, H., 2005. Second-order turbulence closure models for geophysical boundary layers, a review of recent work. Cont. Shelf. Res. 25, 795-827. doi:10.1016/j.csr.2004.08.004.

van Vledder, G.P., 2002. Improved parameterisations of non-linear four-wave interactions for applications in operational wave prediction models. Alkyon Rep. 151, 55pp.

WAMDI Group, 1988. The WAM model- a third generation ocean wave prediction model. J. Phys. Oceanogr. 18, 1775-1810. doi:10.1175/15200485(1988)018<1775:TWMTGO>2.0.CO;2.

Whitham, G.B., 1965. A general approach to linear and non-linear dispersive waves using a lagrangian. J. Fluid. Mech. 22, 273-283. doi:10.1017/S0022112065000745.

1490 Young, I.R., 1999. Wind Generated Ocean Waves. Elsevier Ocean Engineering Series, Elsevier Science. doi:10.1016/S0378-3839(00)00061-2.

Young, I.R., 2006. Directional spectra of hurricane wind waves. J. Geophys. Res. 111, C08020, 14pp. doi:10.1029/2006JC003540. 
Young, I.R., Babanin, A., Zieger, S., 2013. The decay rate of ocean 1495 swell observed by altimeter. J. Phys. Oceanogr. 43, 2322-2333. doi:10.1175/JPO-D-13-083.1.

Young, I.R., Babanin, A.V., 2006. Spectral distribution of energy dissipation of wind-generated waves due to dominant wave breaking. J. Phys. Oceanogr. 36, 379-394. doi:10.1175/JPO2859.1.

Zieger, S., Babanin, A.V., Rogers, W.E., Young, I.R., 2011. Observation-based dissipation and input terms for WAVEWATCH III ${ }^{\mathrm{TM}}$ : implementation and simple simulations, in: Proc. 12th Int. Workshop on Wave Hindcasting and Forecasting, Kohala Coast, HI, 30 Oct - 4 Nov, $12 \mathrm{pp}$.

Zieger, S., Vinoth, J., Young, I.R., 2009. Joint calibration of multi-platform altimeter measurements of wind speed and wave height over the past 20 years. J. Atmos. Ocean. Tech. 26, 2549-2564. doi:10.1175/2009JTECHA1303.1. 
Table 1: WAVEWATCH namelist parameter for observation-based source terms. Coefficients $\left(\mathrm{a}_{1}, \mathrm{a}_{2}, \mathrm{p}_{1}, \mathrm{p}_{2}\right)$ and generic spectral density $(\mathcal{F})$ are for the wave breaking, and whitecapping dissipation terms. Namelist parameter $a_{0}$ controls the flux of energy from the wave to the atmosphere in the case of opposing winds (or winds at large angles) in the parameterization of the input. Parameter $b_{1}$ is a constant coefficient for the swell dissipation $\left(S_{s w l}\right)$ given in equation (23). Similarly, $B_{1}$ is a scaling coefficient in equation (28) which is an alternative form for the non-dimensional coefficient in $\left(S_{s w l}\right)$. Using a value of zero for $a_{0}, b_{1}$, or $B_{1}$ will deactivate the parameterization for swell. Depending on the quality of the wind field, the flux parameterization can be adjusted through parameter FAC (see $\S 3.5$ details). Due to updates to the repository parameters that are not applicable to earlier releases are marked "n/a".

\begin{tabular}{|c|c|c|c|c|c|c|c|c|}
\hline \multirow[b]{3}{*}{ Parameter } & \multirow[b]{3}{*}{ Namelist } & \multirow[b]{3}{*}{ Variable } & \multirow{3}{*}{$\begin{array}{l}\text { v4.18 } \\
\text { default }\end{array}$} & \multicolumn{2}{|c|}{ v5.08 } & \multirow{3}{*}{$\begin{array}{c}\text { CFSR } \\
2006\end{array}$} & \multirow{3}{*}{$\begin{array}{c}\text { NOGAPS } \\
2006\end{array}$} & \multirow{3}{*}{$\begin{array}{l}\text { CFS } \\
2013\end{array}$} \\
\hline & & & & $S_{s w l} \mathrm{w} /$ & 1 scaling & & & \\
\hline & & & & constant & variable & & & \\
\hline $\mathcal{F}=F_{\mathrm{T}}$ & \&SDS6 & SDSET & $\mathrm{T}$ & \multicolumn{2}{|c|}{-} & - & - & - \\
\hline$a_{1}$ & \&SDS6 & SDSA1 & $6.24 \mathrm{E}-7$ & \multicolumn{2}{|c|}{$3.74 \mathrm{E}-7$} & - & - & - \\
\hline$p_{1}$ & \&SDS6 & SDSP1 & 4 & \multicolumn{2}{|c|}{-} & - & - & - \\
\hline$a_{2}$ & \&SDS6 & SDSA2 & $8.74 \mathrm{E}-6$ & \multicolumn{2}{|c|}{$5.24 \mathrm{E}-6$} & - & - & - \\
\hline$p_{2}$ & \&SDS6 & SDSP2 & 4 & \multicolumn{2}{|c|}{-} & - & - & - \\
\hline scaling flag & \&SWL6 & CSTB1 & $\mathrm{n} / \mathrm{a}$ & $\mathrm{T}$ & $\mathrm{F}$ & - & - & - \\
\hline$b_{1}$ & \&SWL6 & SWLB1 & $0.25 \mathrm{E}-3$ & - & $\mathrm{n} / \mathrm{a}$ & - & - & - \\
\hline$B_{1}$ & \&SWL6 & SWLB1 & $\mathrm{n} / \mathrm{a}$ & $\mathrm{n} / \mathrm{a}$ & $0.32 \mathrm{E}-2$ & - & - & - \\
\hline$a_{0}$ & \&SIN6 & SINA0 & 0.04 & - & 0.09 & - & - & - \\
\hline FAC & \&FLX4 & CDFAC & $1.000 \mathrm{E}-4$ & - & - & $1.098 \mathrm{E}-4$ & $1.230 \mathrm{E}-4$ & $1.000 \mathrm{E}-4$ \\
\hline
\end{tabular}


Table 2: Model-data comparison for Lake Michigan hindcast at NDBC buoy 45007 for selected source terms. Comparison for integral parameters wave height $\mathrm{H}_{\mathrm{s}}$, mean wave direction $\langle\theta\rangle$, peak period $T_{p}$, and the mean periods $T_{01}, T_{02}, T_{-10}$ by means of scatter statistics: Pearson's correlation coefficient $\rho$, root-mean-square error e, bias b, scatter index SI (in \%), and slope of least-square regression forced through the origin $\mathrm{m}_{\mathrm{o}}$. A positive bias signals that the model overestimates the parameter compared to observations. Integral parameters and error statistics are defined in Appendix A.

\begin{tabular}{|c|c|c|c|c|c|c|c|c|c|c|c|c|c|c|c|}
\hline & $\rho$ & e & $\mathrm{b}$ & SI & $\mathrm{m}_{\mathrm{o}}$ & $\rho$ & e & $\mathrm{b}$ & SI & $\mathrm{m}_{\mathrm{o}}$ & $\rho$ & e & $\mathrm{b}$ & SI & $\mathrm{m}_{\mathrm{o}}$ \\
\hline & \multicolumn{5}{|c|}{$\mathrm{H}_{\mathrm{s}}$} & \multicolumn{5}{|c|}{$\langle\theta\rangle$} & \multicolumn{5}{|c|}{$\mathrm{T}_{\mathrm{p}}$} \\
\hline TC96 & 0.94 & 0.21 & -0.08 & 20 & 0.88 & 0.97 & 26.2 & -4.37 & 13 & 0.97 & 0.84 & 0.85 & -0.57 & 13 & 0.87 \\
\hline TEST451 & 0.96 & 0.17 & -0.04 & 17 & 0.93 & 0.97 & 25.8 & -4.26 & 13 & 0.97 & 0.87 & 0.59 & -0.15 & 12 & 0.96 \\
\hline \multirow[t]{2}{*}{ BYDRZ } & 0.95 & 0.18 & -0.02 & 19 & 0.99 & 0.97 & 25.8 & -4.07 & 13 & 0.97 & 0.85 & 0.66 & -0.16 & 14 & 0.96 \\
\hline & \multicolumn{5}{|c|}{$\mathrm{T}_{01}$} & \multicolumn{5}{|c|}{$\mathrm{T}_{02}$} & \multicolumn{5}{|c|}{$\mathrm{T}_{-10}$} \\
\hline TC96 & 0.90 & 0.44 & -0.29 & 8 & 0.92 & 0.90 & 0.41 & -0.27 & 8 & 0.92 & 0.90 & 0.48 & -0.31 & 9 & 0.92 \\
\hline TEST451 & 0.92 & 0.30 & -0.09 & 7 & 0.97 & 0.92 & 0.29 & -0.10 & 7 & 0.97 & 0.92 & 0.34 & -0.08 & 8 & 0.98 \\
\hline BYDRZ & 0.91 & 0.33 & -0.10 & 8 & 0.97 & 0.91 & 0.31 & -0.12 & 7 & 0.97 & 0.91 & 0.36 & -0.07 & 9 & 0.98 \\
\hline
\end{tabular}

Table 3: Cost of running different source terms. Expense of each source term package is given relative to former WAVEWATCH source terms TC96. Higher values mean that the source term package is more expensive to run. Absolute run times are given in hours (h) and minutes (') for the global hindcast described in text (see section §3.5).

\begin{tabular}{lrrrrr}
\hline & WAM3 & TC96 & WAM4+ & TEST451 & BYDRZ \\
\hline Relative expense & $88.1 \%$ & $100 \%$ & $96.4 \%$ & $121.7 \%$ & $98.5 \%$ \\
2006 hindcast (8 processors) & $17 \mathrm{~h} 30$ & $19 \mathrm{~h} 51^{\prime}$ & $19 \mathrm{~h} 08^{\prime}$ & $24 \mathrm{~h} 10^{\prime}$ & $19 \mathrm{~h} \mathrm{33}$ \\
\hline
\end{tabular}




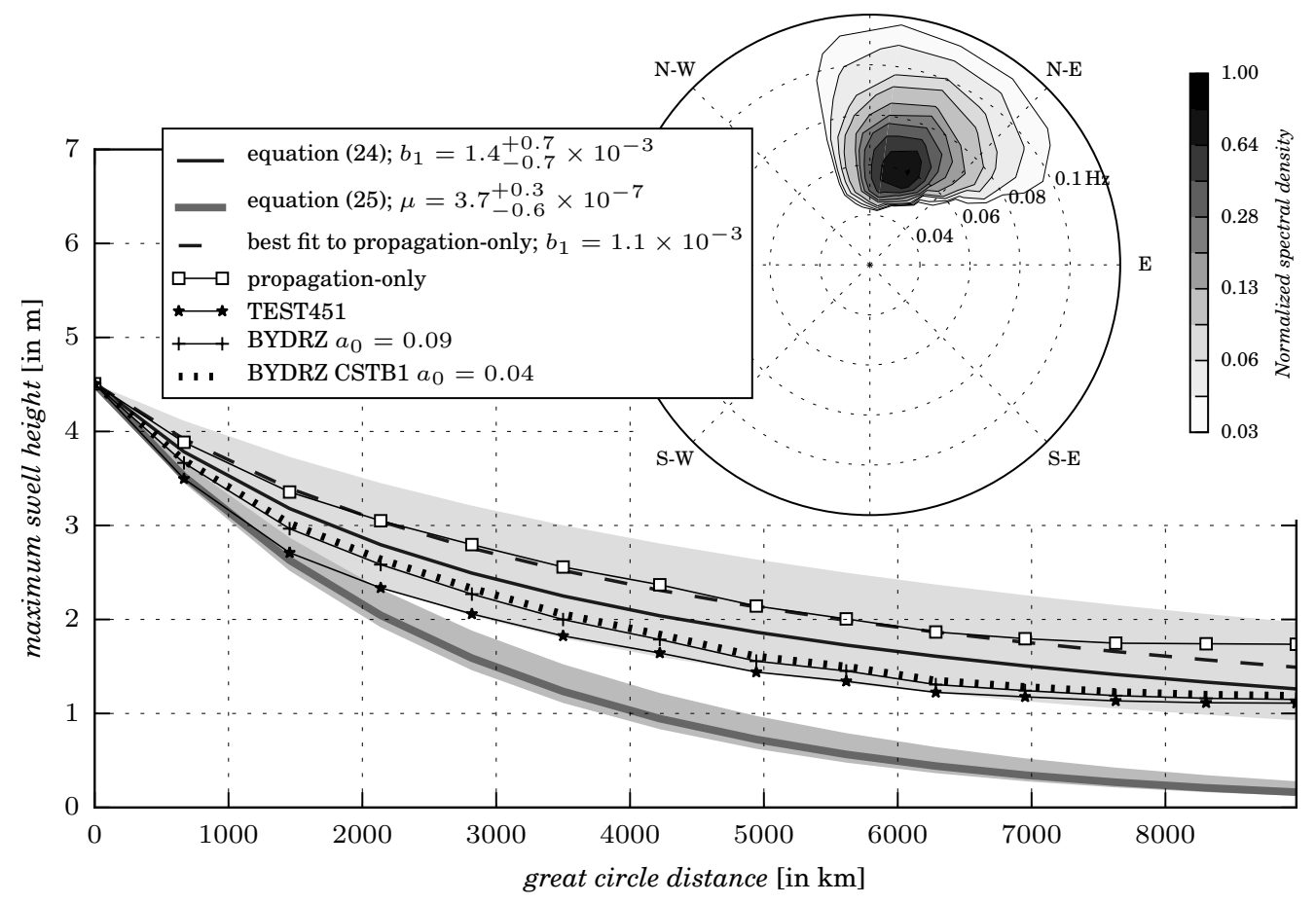

Figure 1: Attenuation of swell as a function of distance propagated along a great circle (from $160^{\circ} \mathrm{W} 30^{\circ} \mathrm{S}$ to $145^{\circ} \mathrm{W} 50^{\circ} \mathrm{N}$ ). The initial spectrum (normalized; upper right panel) represents the storm event modelled on 1 June 2013 00:00 UTC. Empirical coefficients from equation (24) (Young et al., 2013) and equation (25) (Collard et al., 2009) are shown with respect to their confidence limits (shaded areas for lines one and two in legend). The reduction of wave height due to dispersion in a propagation-only test (third order scheme PR3 UQ) with source terms explicitly turned off is depicted by a solid line with squares. The dashed line shows the best fit of equation (24) to the propagation-only test. Lines five through seven show different swell parameterizations including TEST451 (Ardhuin et al., 2010 ) and the one presented in equation (23) with a steepness dependent $b_{1}(28)$ and with a constant $b_{1}$ (CSTB1, dotted line). 


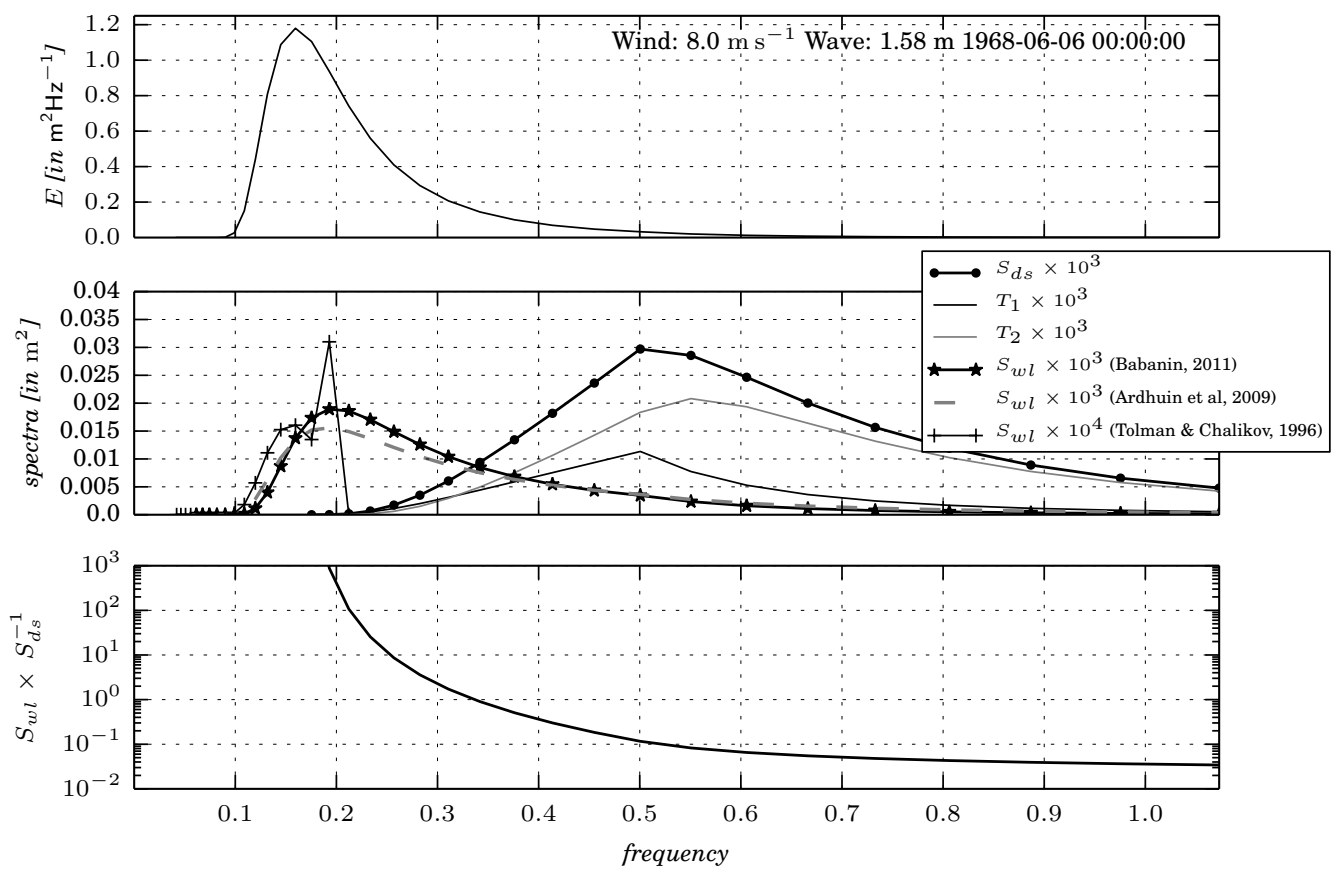

Figure 2: Dissipation source terms computed from prescribed parametric spectrum (top panel) for wind speed of $8 \mathrm{~m} \mathrm{~s}^{-1}$ and peak frequency of $0.16 \mathrm{~Hz}$. The second panel shows source terms as a function of frequency $f$ for wave-breaking, whitecapping dissipation $S_{d s}=T_{1}+T_{2}$ and swell dissipation $S_{w l}$ as proposed by Babanin (2011, with $\left.b_{1}=0.00025\right)$, Ardhuin et al. (2009, with $\left.f_{e}=0.040\right)$, and Tolman and Chalikov (1996, negative part of wind input). The bottom panel depicts the ratio of swell dissipation to wave-breaking, whitecapping dissipation. 

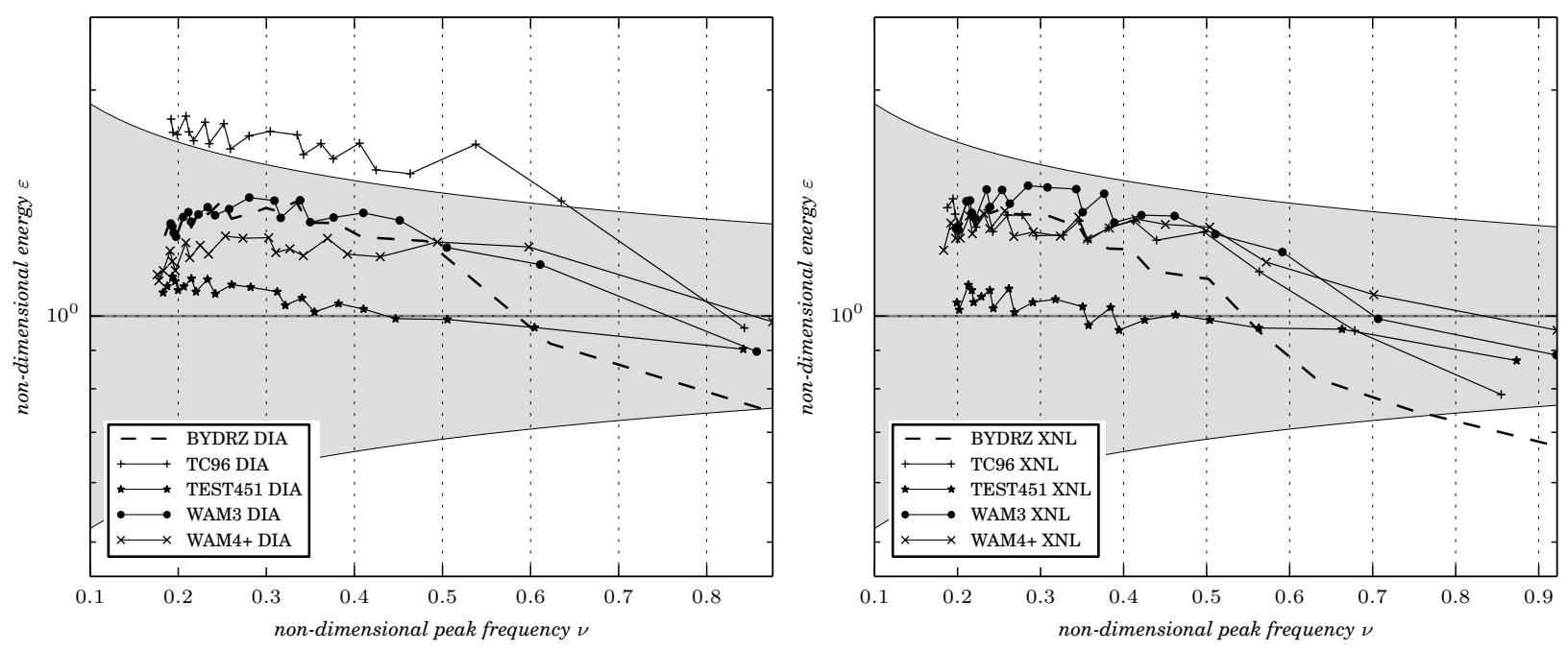

Figure 3: Non-dimensional wave energy $\varepsilon=\epsilon^{2} g^{2} U_{10}^{-4}$ as a function of non-dimensional peak frequency $\nu=f_{p} U_{10} g^{-1}$ for selected source terms with (left) approximate and (right) exact non-linear interaction computation (wind speed: $12 \mathrm{~m} \mathrm{~s}^{-1}$ ). Dependences are normalised by the parameterisation of Babanin and Soloviev (1998a) with shaded areas showing $95 \%$ confidence limits. 

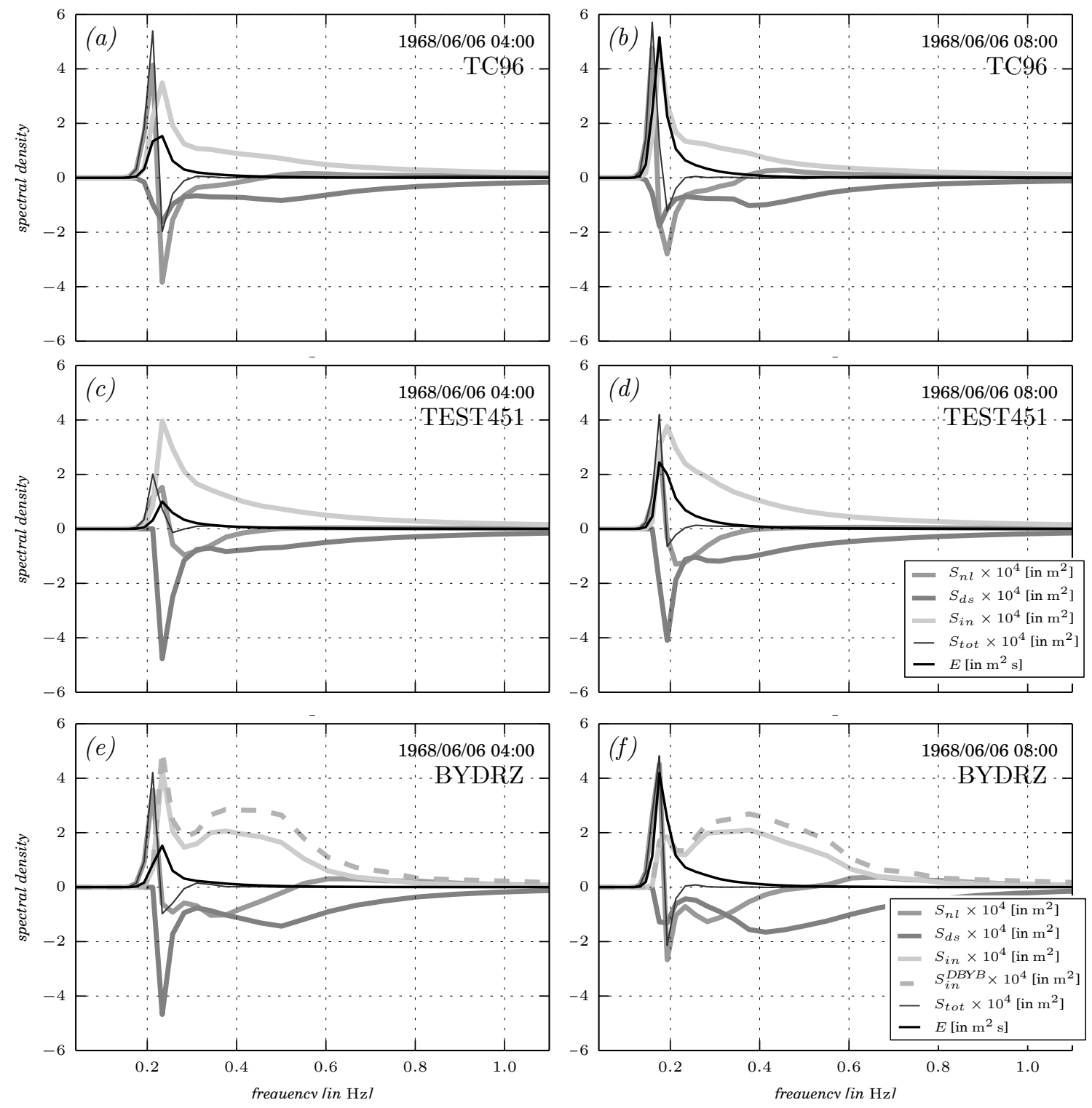

Figure 4: Source term balance for the duration-limited academic test after 4 hours (left panels) and 8 hours (right panels). Source term are computed with exact non-linear wave-wave interaction (XNL) and for parameterizations TC96 (a-b), TEST451 (c-d) and BYDRZ (e-f). The effect of the constraint applied to the Donelan et al. (2006) input term $S_{i n}^{\text {DBYB }}$ is depicted for the BYDRZ source terms $(\mathrm{e}-\mathrm{f})$. 

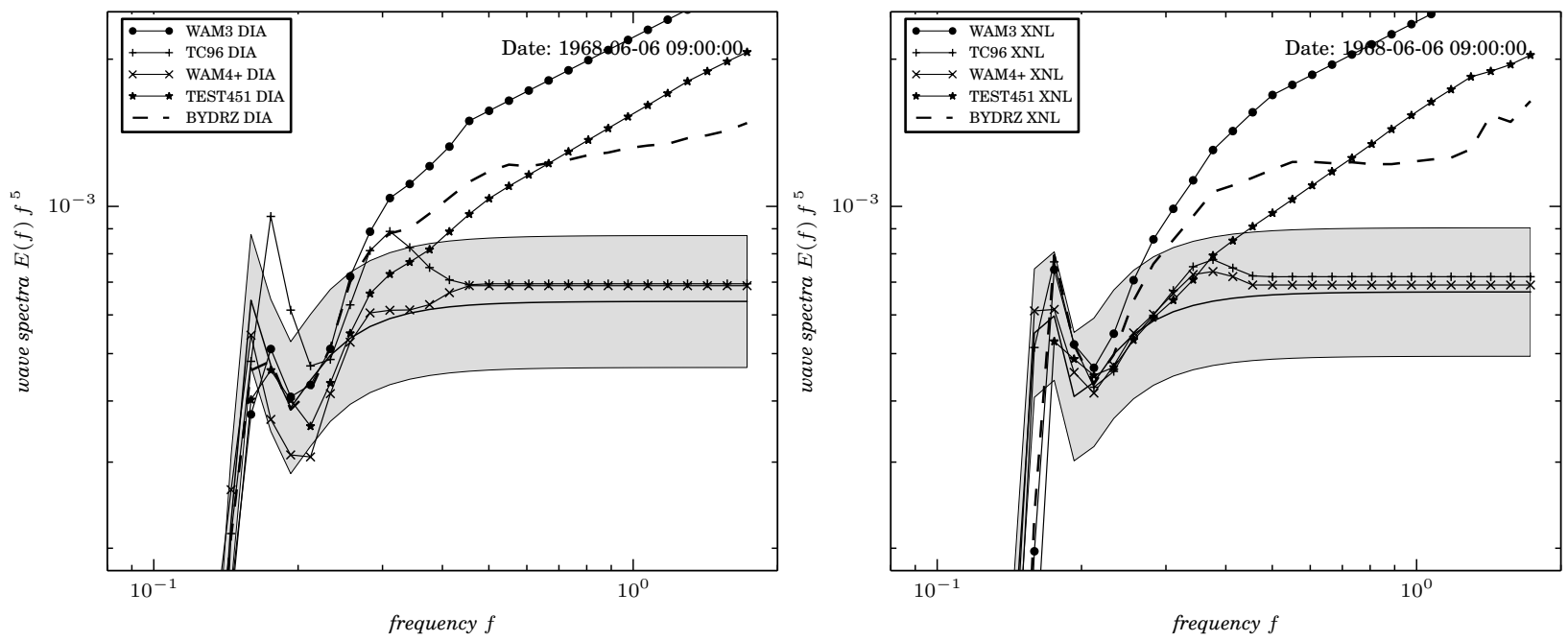

Figure 5: Level of the spectral tail (no cut-off frequency) versus frequency after 9 hours of simulation. Shaded areas represent the parameterization of equilibrium interval level $\alpha$ with 95\% confidence limits (Babanin and Soloviev, 1998a). Computation shown for (left) approximate and (right) exact non-linear wave-wave interaction. 

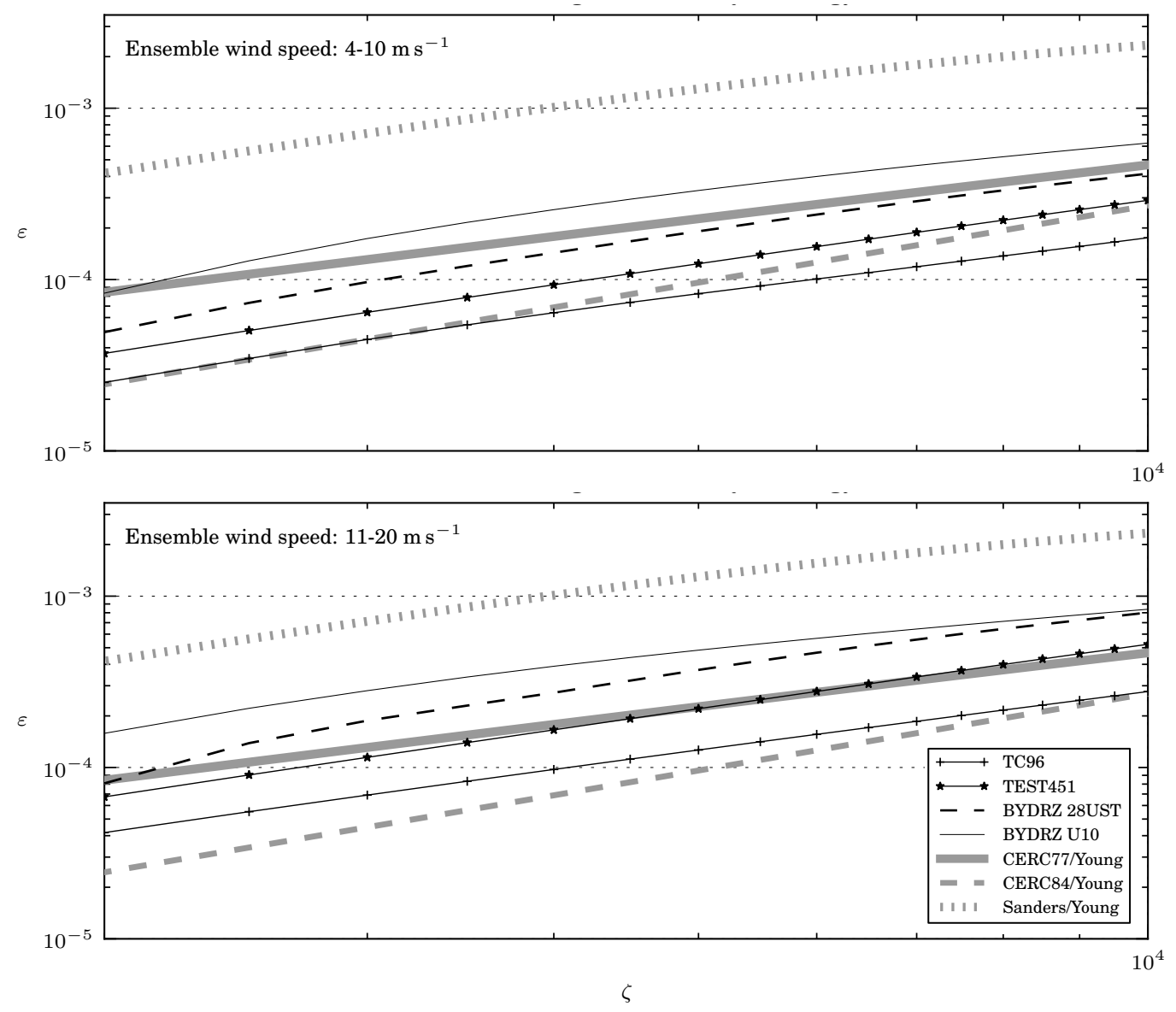

Figure 6: Duration-limited growth in the form of ensemble average of non-dimensional time $\zeta$ and non-dimensional energy $\varepsilon$ for selected source terms. The top panel shows ensemble mean growth curves for low to moderate winds $\left(4-10 \mathrm{~m} \mathrm{~s}^{-1}\right)$ while the bottom panel shows ensemble mean for moderate to high winds $\left(11-20 \mathrm{~m} \mathrm{~s}^{-1}\right)$. In addition, three empirical models are shown (Young, 1999, pp.110-112). Simulation with approximate non-linear interaction (DIA). 

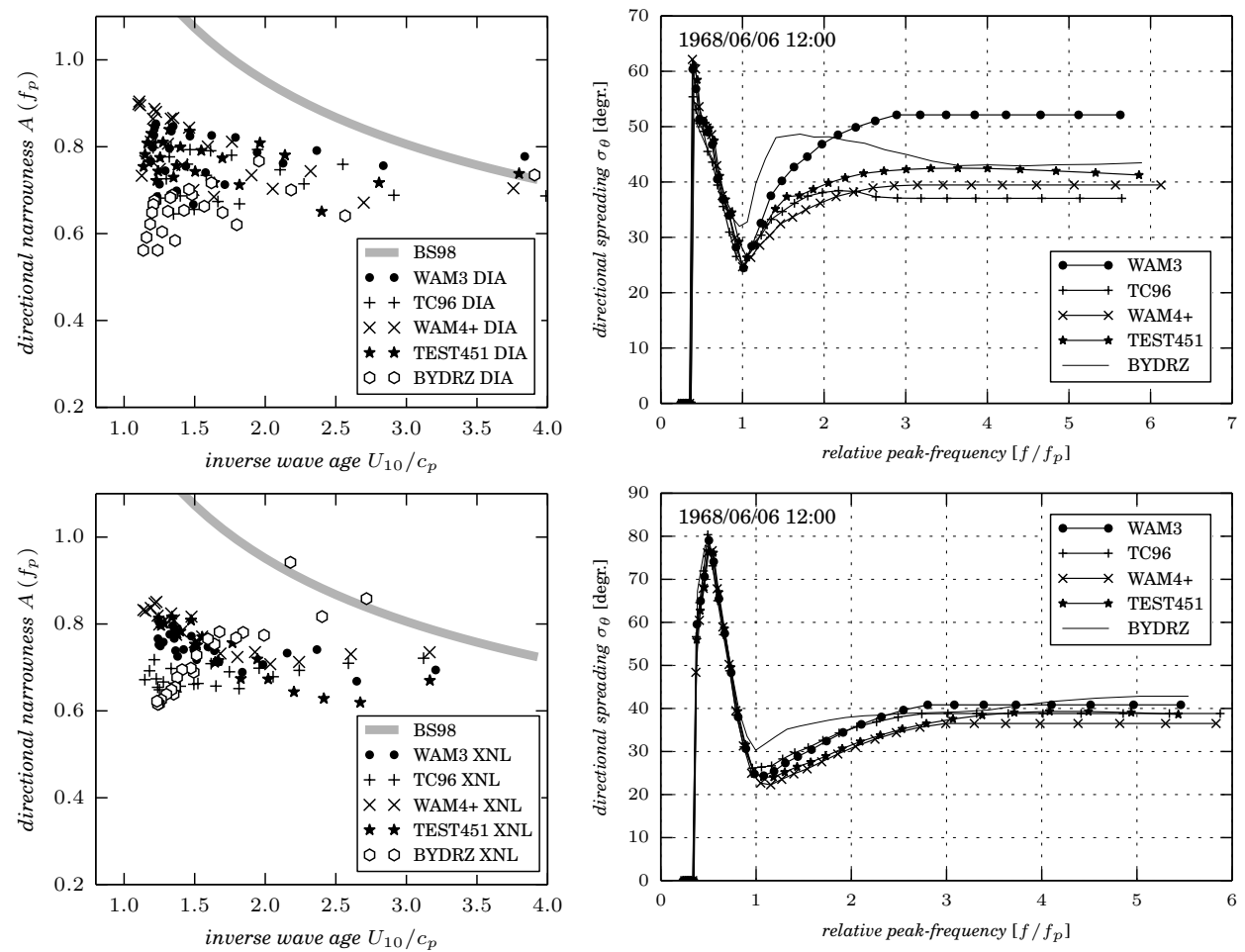

Figure 7: Directional narrowness parameter $A\left(f_{p}\right)$ (left column) as a function of inverse wave age $U_{10} / c_{p}$ where the solid line shows the empirical dependence BS98 (Babanin and Soloviev, 1998b). The right panels show directional spread $\sigma_{\theta}$ (Kuik et al., 1988) as a function of relative peak frequency $f / f_{p}$ for the duration-limited idealized test with $12 \mathrm{~m} \mathrm{~s}^{-1}$ winds after $12 \mathrm{~h}$. Directional dependence is given for (top panels) approximate and (bottom panels) exact non-linear wave-wave interaction. 

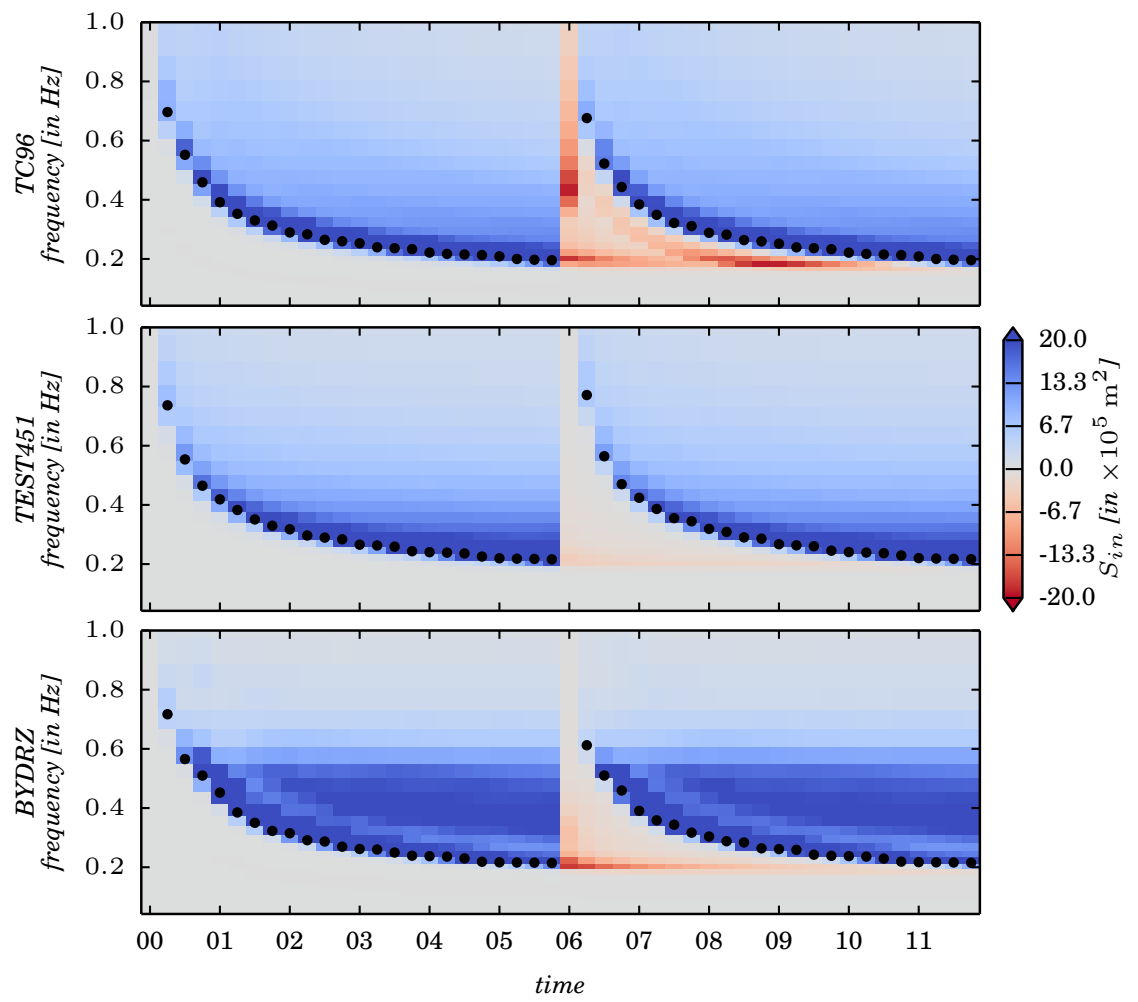

Figure 8: Evolution of input source term $S_{i n}$ as function of time with exact non-linear four-wave interaction computation for the duration-limited academic test with the wind $\left(12 \mathrm{~m} \mathrm{~s}^{-1}\right)$ instantly turning by $180^{\circ}$ after 6 hours. Selected source terms (from top) are TC96, TEST451, and BYDRZ with dots indicating the peak of the spectrum as a function of time. 

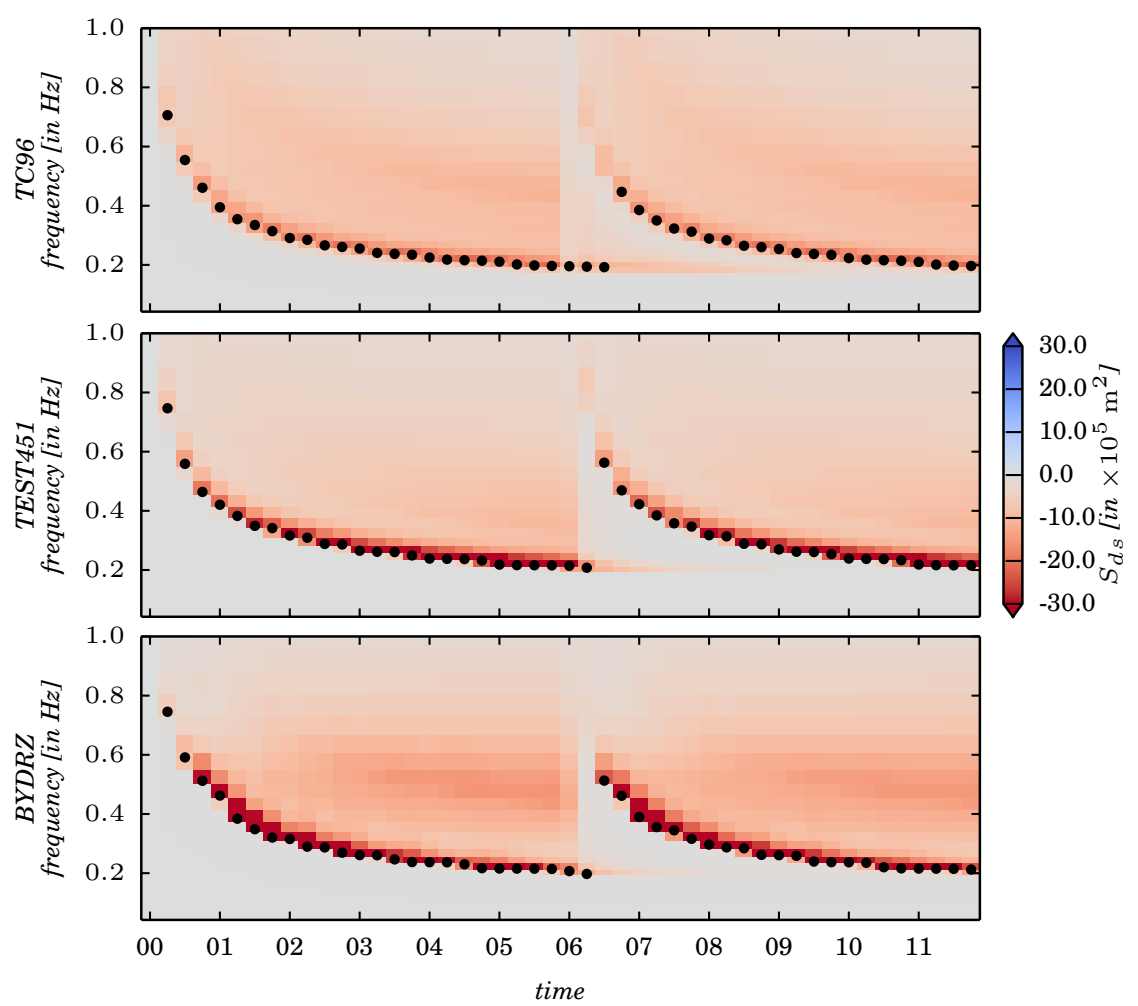

Figure 9: Similar to Fig. 8, evolution of dissipation source term $S_{d s}$ as function of time with exact non-linear four-wave interaction computation for the duration-limited academic test with the wind $\left(12 \mathrm{~m} \mathrm{~s}^{-1}\right)$ instantly turning by $180^{\circ}$ after 6 hours. 


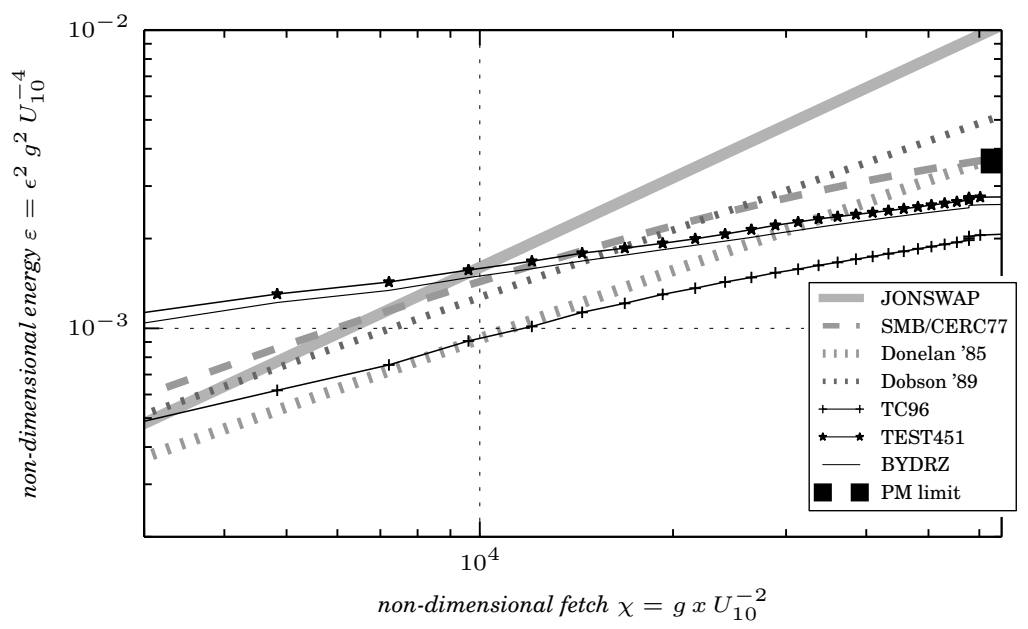

Figure 10: Growth rate along the diagonal for slanting fetches. Non-dimensional energy $\varepsilon$ as a function of the non-dimensional fetch $\chi$ for $12 \mathrm{~ms}^{-1}$ winds and exact wave wave interaction calculation (XNL). Growth curves are shown for selected source terms: TC96, TEST451, and BYDRZ and selected fetch-limited empirical models. 


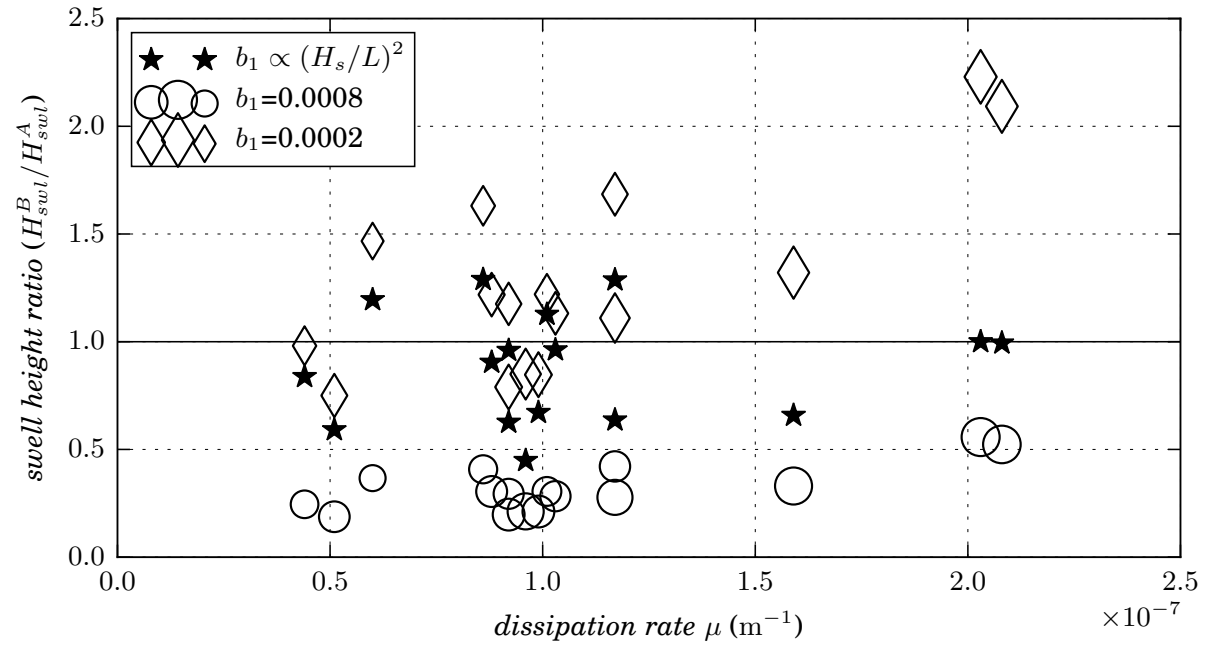

Figure 11: Ratio of swell heights computed over a distance of $10,000 \mathrm{~km}$ plotted as a function of dissipation rate $\mu$ from Ardhuin et al. (2009, auxiliary online material). Swell heights are potted for $H_{s w l}^{A}$ (equation (25)), and for $H_{s w l}^{B}$ (equation (24)). Marker size for circles and diamonds correspond to steepness (wave height $(H)$ over wave length $(L)$ ) and stars depict the ratio based on a $b_{1}$ coefficient proportional to steepness squared. 


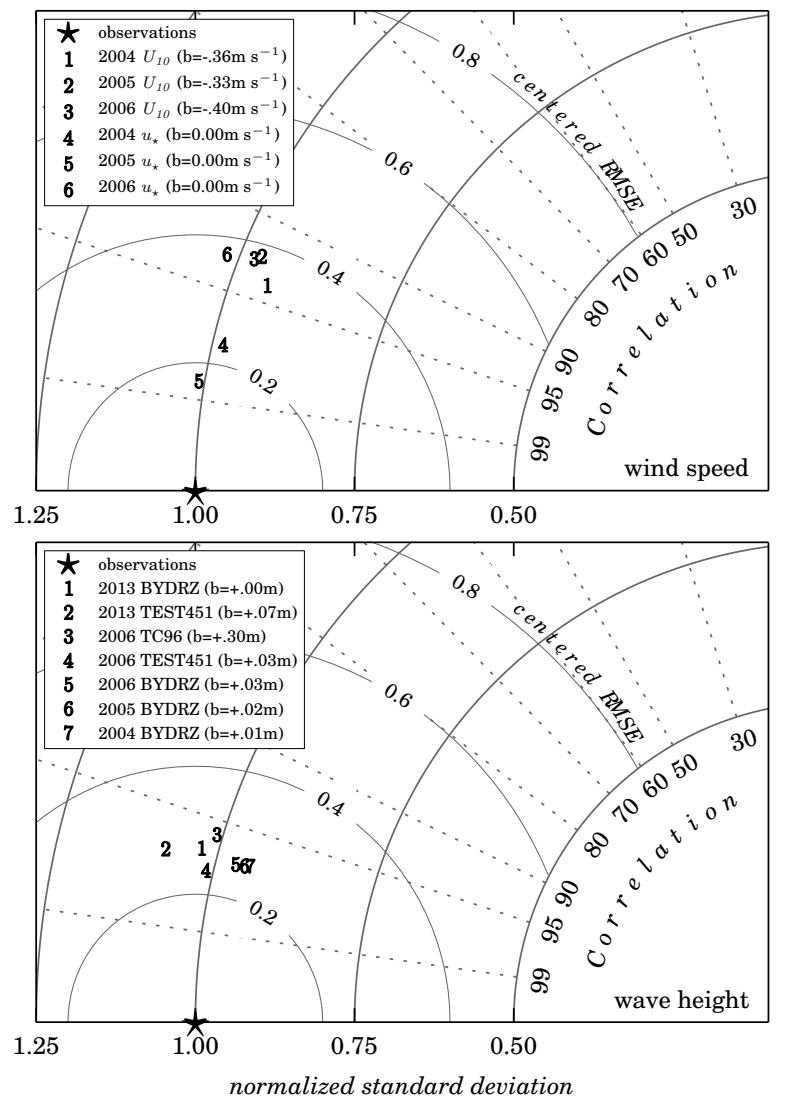

Figure 12: BLT diagrams depicting the model skill for (top) wind speed and (bottom) wave height in reference to observations by altimeters for the years 2004 to 2006 . The upper panel shows the quality of the input by means of wind speed $U_{10}$ and adjusted friction velocity $u_{\star}$ (see text for details). Values for mean bias $b$ between model and observations are listed in the legend. 

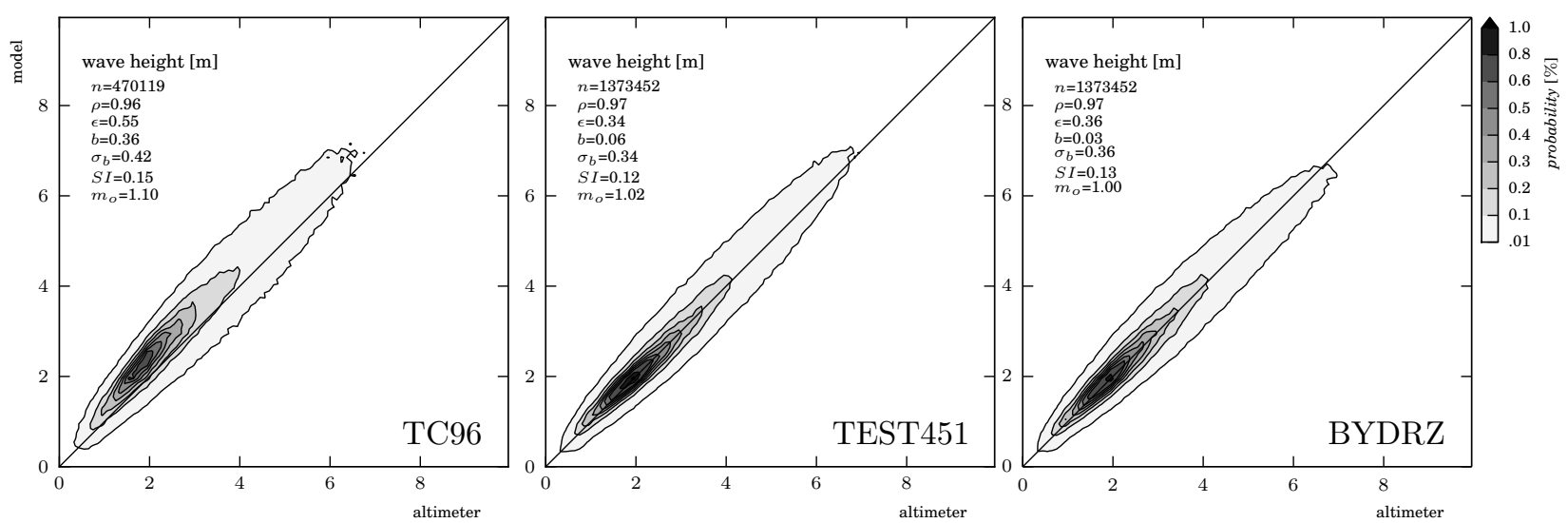

Figure 13: Scatter density plots of wave height for the 2006 global hindcast. From left: default source terms TC96, recently implemented TEST451, and new BYDRZ source terms. Reanalysis winds were bulk-adjusted (see text for details) for models TEST451 and BYDRZ. Each legend contains scatter statistics equivalent to those in the Lake Michigan hindcast (see Tab. 2 caption). 

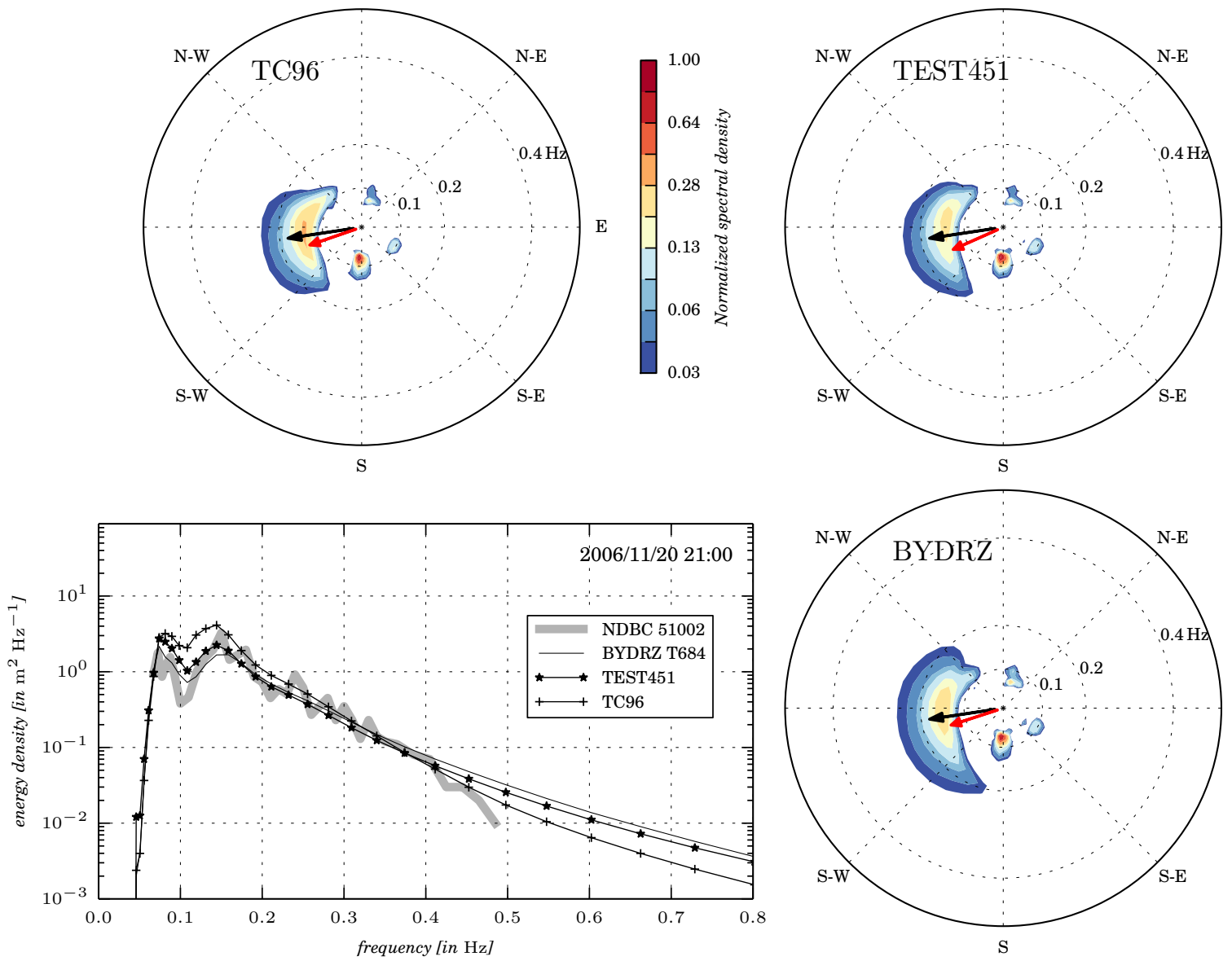

Figure 14: Comparison between observed and modelled spectra on 20 November 2006 21:00 UTC at site NDBC 51002 located southwest of Big Island, Hawaii. The black arrow shows the wind direction ( $81^{\circ} ; 9 \mathrm{~m} \mathrm{~s}^{-1}$ model (see text for adjustment), $7 \mathrm{~m} \mathrm{~s}^{-1}$ observed) whereas the mean wave direction is shown in red. Measured wave height is $2.01 \mathrm{~m}$ and the models estimated wave height (mean wave direction given in meteorological convention) of $2.62 \mathrm{~m}\left(71^{\circ}\right), 2.12 \mathrm{~m}\left(66^{\circ}\right)$ and $1.96 \mathrm{~m}\left(71^{\circ}\right)$ for source terms TC96, TEST451 and BYDRZ, respectively. 

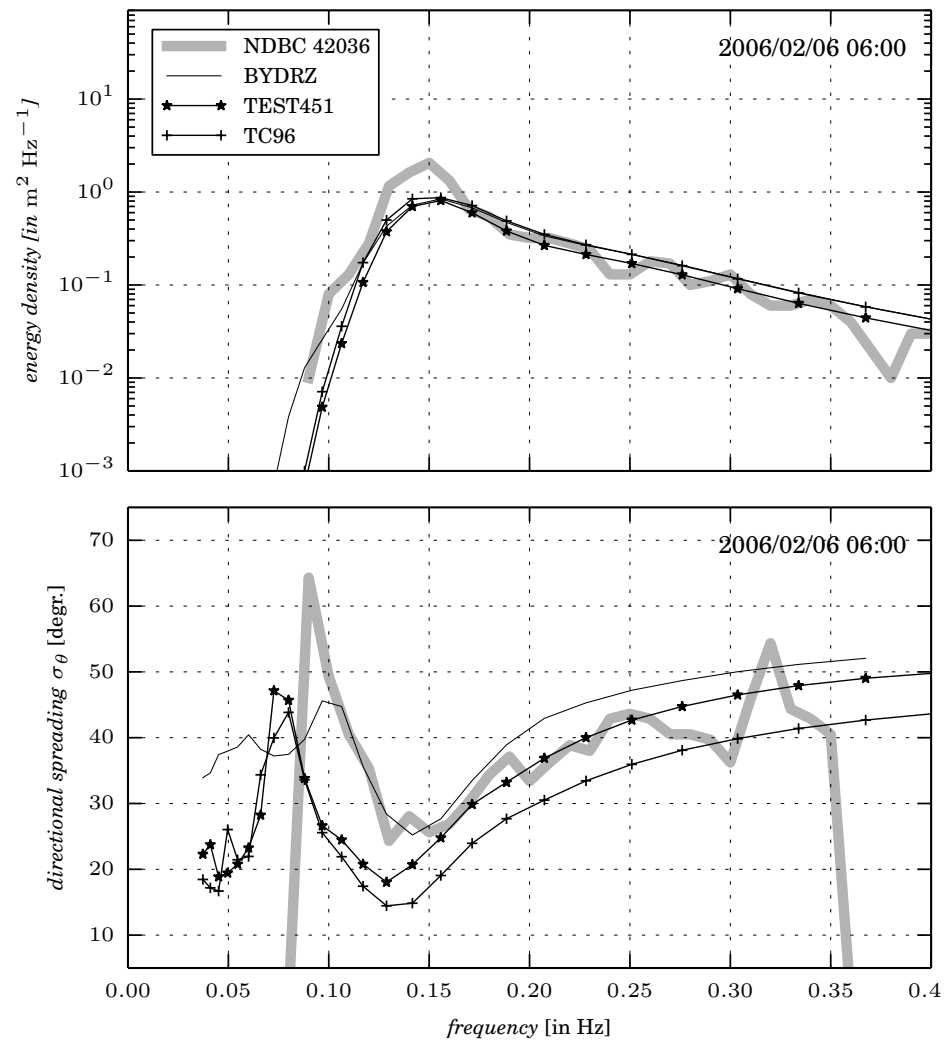

Figure 15: Comparison between observed and modelled spectra on 6 February 2006 06:00 UTC at site NDBC 42036 located 112 nautical miles west-north-west of Tampa, Florida. Measured wave height is $1.31 \mathrm{~m}$ (mean wave direction $275^{\circ}$ ) and the models estimated wave height (mean wave direction given in meteorological convention) of $1.16 \mathrm{~m}\left(281^{\circ}\right), 1.04 \mathrm{~m}$ $\left(280^{\circ}\right)$ and $1.13 \mathrm{~m}\left(277^{\circ}\right)$ for source terms TC96, TEST451 and BYDRZ, respectively. 

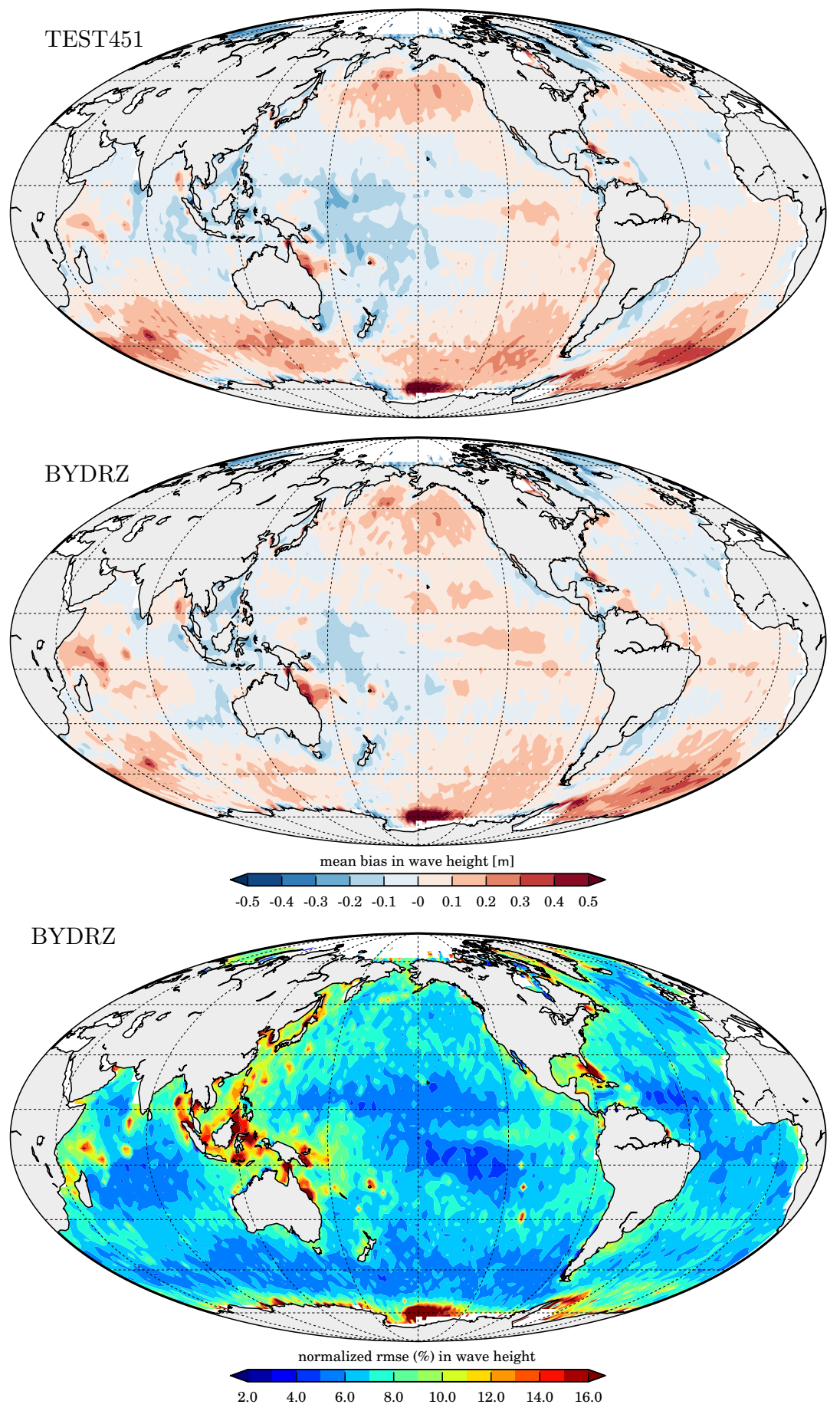

Figure 16: Mean spatial bias in wave height for the 2006 global hindcast. Results are shown for (top) TEST451 source terms and (center B BYYDZ parameterization. The bottom panel shows the normalized root-mean-square error for wave height for the BYDRZ source term. Contour lines derived from mean values across $2^{\circ} \times 2^{\circ}$ bins. 

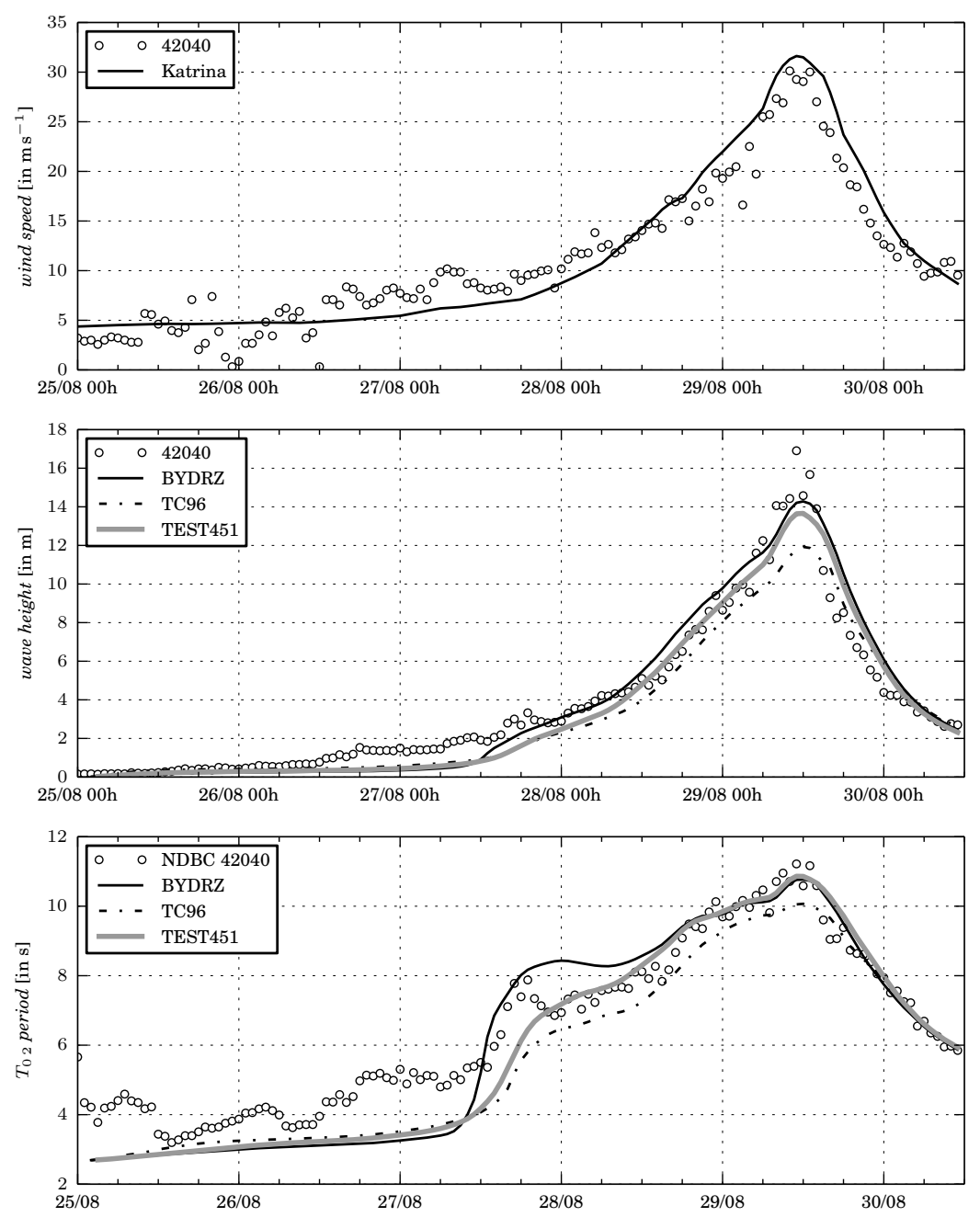

Figure 17: Time history of wind speed (top panel), significant wave height (second panel) and mean wave period $T_{02}$ (bottom panel) at NDBC 42040 site during passage of Hurricane Katrina in August 2005. Model results for TC96, TEST451 and BYDRZ parameterizations are shown. Wind speed was corrected to $10 \mathrm{~m}$ reference height using a logarithmic profile of the boundary layer (Zieger et al., 2009). 


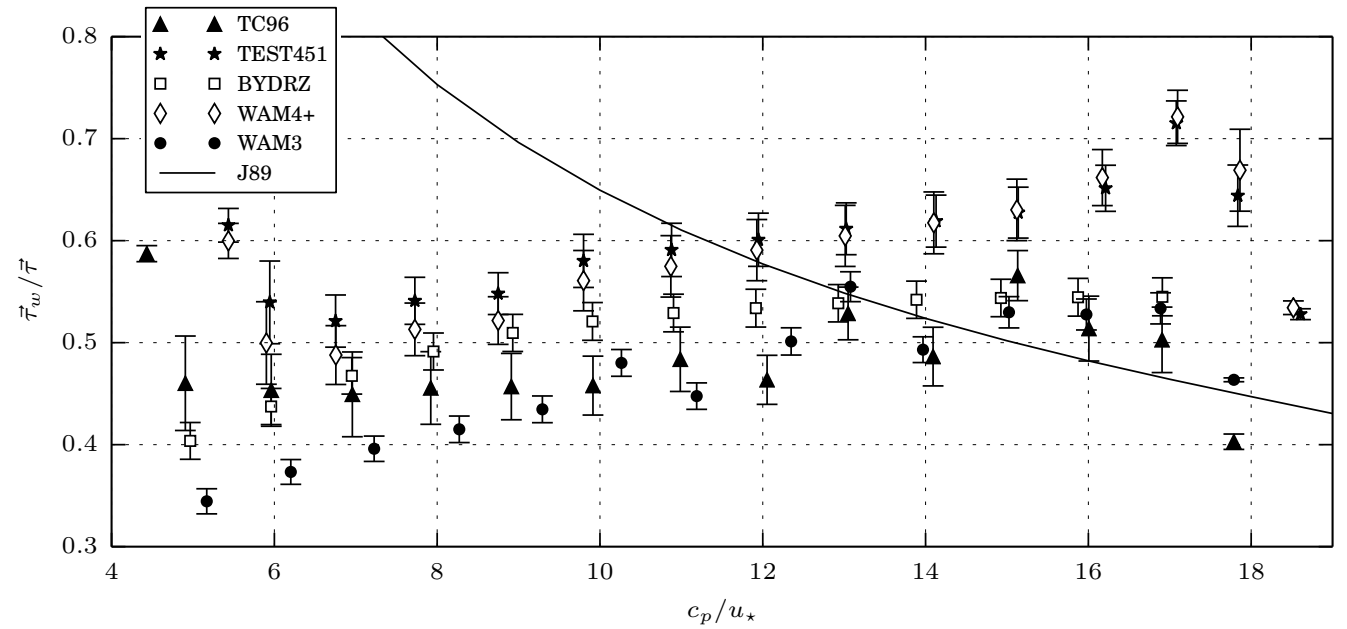

Figure 18: Plot of wave age $c_{p} / u_{\star}$ versus the ratio of wave-induced stress $\vec{\tau}_{w}$ to the total stress: $\vec{\tau}$. Error bars indicate the variance of groups of wave age (binned to natural numbers). Based on a range of prescribed JONSWAP spectra (WAVEWATCH default coefficients) varying in peak frequency and wind speed $U_{10}=[6,20]$, stresses were calculated for source terms TC96, TEST451, BYDRZ as well as for WAM3 and WAM4+ physics. The solid line (J89) indicates the normalized wave stress dependence with a power-law fit thourgh JONSWAP data (Janssen, 1989, Eq. (7)-(8), (10)). 